\title{
Impact of antiviral therapy on hepatocellular carcinoma and mortality in patients with chronic hepatitis C: systematic review and meta-analysis
}

\author{
Chang Seok Bang ${ }^{1}$ and II Han Song ${ }^{2^{*}}$
}

\begin{abstract}
Background: The long-term clinical outcomes of antiviral therapy for patients with chronic hepatitis $C$ are uncertain in terms of hepatitis $\mathrm{C}$ virus (HCV)-related morbidity and mortality according to the response to antiviral therapy. This study aimed to assess the impact of antiviral treatment on the development of HCC and mortality in patients with chronic HCV infection.

Methods: A systematic review was conducted for studies that evaluated the antiviral efficacy for patients with chronic hepatitis C or assessed the development of HCC or mortality between SVR (sustained virologic response) and non-SVR patients. The methodological quality of the enrolled publications was evaluated using Risk of Bias table or Newcastle-Ottawa scale. Random-effect model meta-analyses and meta-regression were performed. Publication bias was assessed.

Results: In total, 59 studies (4 RCTs, 15 prospective and 40 retrospective cohort studies) were included. Antiviral treatment was associated with reduced development of HCC (vs. no treatment; OR 0.392, 95\% Cl 0.275-0.557), and this effect was intensified when SVR was achieved (vs. no SVR, OR: 0.203, 95\% Cl 0.164-0.251). Antiviral treatment was associated with lower all-cause mortality (vs. no treatment; OR 0.380, 95\% Cl 0.295-0.489) and liver-specific mortality (OR 0.363, 95\% Cl 0.260-0.508). This rate was also intensified when SVR was achieved [all-cause mortality (vs. no SVR, OR 0.255, 95\% Cl 0.199-0.326), liver-specific mortality (OR 0.126, 95\% Cl 0.094-0.169)]. Sensitivity analyses revealed robust results, and a small study effect was minimal.
\end{abstract}

Conclusions: In patients with chronic hepatitis C, antiviral therapy can reduce the development of HCC and mortality, especially when SVR is achieved.

Keywords: Antiviral therapy, Chronic hepatitis C, Hepatocellular carcinoma, Mortality, Sustained virologic response

\section{Background}

Antiviral treatment for chronic hepatitis $\mathrm{C}(\mathrm{CHC})$ aims to prevent hepatitis $\mathrm{C}$ virus ( $\mathrm{HCV}$ )-related morbidity and mortality, including complications of liver fibrosis or cirrhosis and the development of hepatocellular carcinoma (HCC). Treatment reduces the degree of necroinflammation of the liver and induces regression of hepatic fibrosis [1]. Although direct-acting antivirals

\footnotetext{
* Correspondence: ihsong21@dankook.ac.kr

2Division of Hepatology, Department of Internal Medicine, Dankook

University College of Medicine, Cheonan, Korea, Republic of Korea

Full list of author information is available at the end of the article
}

have recently emerged as a promising therapy, conventional interferon (IFN) or pegylated IFN (PegIFN) with or without ribavirin (RBV) has been used as the standard treatment for curing HCV.

A sustained virologic response (SVR) is the surrogate indicator for eradicating $\mathrm{HCV}$ and is considered to be "cure" [2]. SVR24 or SVR12, which is the state of undetectable HCV RNA in a sensitive assay with a lower limit of detection $<50 \mathrm{IU} / \mathrm{mL}$ at week 24 or 12 after the end of treatment are accepted as an endpoint of treatment [3]. 
The evolution of $\mathrm{CHC}$ is slow, and there is no specific symptom before progression to liver fibrosis. Due to delayed diagnosis of HCV-related chronic liver disease such as chronic hepatitis or liver fibrosis, it is difficult to start an anitviral treatment in the early stage of the disease. Previous study has demonstrated an achievement of SVR was associated with less risk for mortality (risk ratio 0.16 ) and development of HCC (risk ratio 0.37) [4]. However, the majority of studies assessed short-term prognosis and the long-term clinical outcomes of antiviral therapy for patients with chronic hepatitis $\mathrm{C}$ are uncertain in terms of HCV-related morbidity and mortality, including disease progression to advanced hepatic fibrosis or cirrhosis, hepatic decompensation, HCC, and liver-specific death, especially according to the response to antiviral therapy. Moreover, viral replication of $\mathrm{HCV}$ is not known to be directly related to $\mathrm{HCC}$ development [4].

The aim of this study was to assess the impact of antiviral treatment on the development of $\mathrm{HCC}$ and mortality in patients with $\mathrm{CHC}$.

\section{Methods}

This systematic review and meta-analysis fully adhered to the principle of PRISMA (Preferred Reporting Items for Systematic reviews and Meta-Analyses) checklist.

\section{Literature searching strategy}

PubMed, Embase, and the Cochrane Library were searched using common keywords associated with chronic hepatitis $\mathrm{C}, \mathrm{HCC}$, or SVR (from inception to April 2016) by 2 independent evaluators (C.S.B. and Y.J.Y.). Medical Subject Headings (MeSH) or Emtree keywords were selected for searching of electronic databases. The keywords included 'hepatitis C, 'HCV', 'hepatocellular carcinoma, ' $\mathrm{HCC}$, 'sustained virologic response', 'SVR' and 'mortality'. These keywords were combined for a searching strategy using Boolean operators. The abstracts of all identified studies were reviewed to exclude irrelevant articles. Full-text reviews were performed to determine whether the inclusion criteria were satisfied by the remaining studies and the bibliographies of relevant articles were reviewed to identify additional studies. Disagreements between the evaluators were resolved by discussion or consultation with a third evaluator (I.H.S.). The detailed searching strategy is described in Table 1.

\section{Selection criteria}

We included randomized or non-randomized studies that met the following criteria: 1 . Study designed to evaluate the efficacy of antiviral treatment on the development of HCC or mortality in CHC patients and a control group, or in $\mathrm{CHC}$ patients with SVR and the no SVR group; 2. Publications on human subjects; 3. Fulltext publication; and 4. English language. Studies that
Table 1 Clinical data of included studies

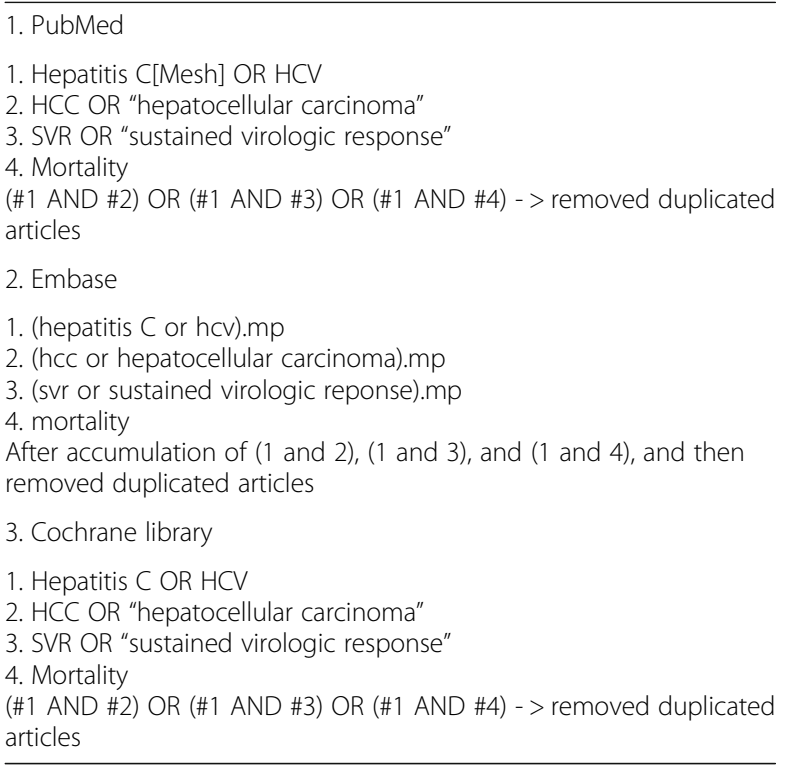

met the all of the inclusion criteria were sought and selected. The exclusion criteria were as follows: 1 . Incomplete data; 2. Review article; 3. Animal study; 4. Letter or case article; or 5. Abstract only publication. Studies meeting at least 1 of the exclusion criteria were excluded from this analysis.

\section{Methodological quality}

The methodological quality of the enrolled publications was assessed using the Risk of Bias table for randomized studies and the Newcastle-Ottawa Scale for nonrandomized studies. The Risk of Bias was assessed as described in the Cochrane handbook by recording the method used to generate the randomization sequence, allocation concealment, determination of whether blinding was implemented for participants or staff, and evidence of selective reporting of the outcomes [5]. Review Manager version 5.3.3 (Revman for Windows 7, the Nordic Cochrane Centre, Copenhagen, Denmark) was used to generate the Risk of Bias table. The Newcastle-Ottawa scale is categorized into three parameters: the selection of the study population, the comparability of the groups, and the ascertainment of the exposure or outcome. Each parameter consists of subcategorized questions: selection $(n=4)$, comparability $(n=1)$, and exposure or outcome ( $n$ $=3$ ) $[6,7]$. Stars that are awarded for each item serve as a quick visual assessment of the methodological quality of the studies. A study can be graded a maximum of 9 stars, which indicates the highest quality. Two of the evaluators (C.S.B. and Y.J.Y.) independently assessed the methodological quality of all studies, and any disagreements between the evaluators were resolved by discussion or consultation with a third evaluator (I.H.S.). 


\section{Primary and modifier-based analyses}

The following questions were primary topic of this meta-analyses: In patients with $\mathrm{CHC}, 1$. Does the antiviral treatment reduce the development of HCC? 2. Does the antiviral treatment reduce all-cause or 3. liverspecific mortality? 4. Does the achievement of SVR reduce the development of HCC? 5. Does the achievement of SVR reduce all-cause or 6 . liver-specific mortality?

The analysis was performed as 6 distinct metaanalyses to answer the 6 questions described above. Two evaluators (C.S.B. and Y.J.Y.) independently used the same data fill-up form to collect the primary summary outcome and modifiers in each study. The outcome was the relative rate of the development of $\mathrm{HCC}$ or mortality between antiviral treatment and the control groups, or the SVR and no SVR groups. These ratios were extracted and evaluated by odds ratios (ORs). Sensitivity analyses, including cumulative and one study removed analyses were performed to confirm the robustness of the main analysis results. These analyses were calculated in the order of publication year or effect size to find whether the time trend exists or which study is more or less influential in the pooled estimate. We also performed a meta-ANOVA and meta-regression to identify the reason of heterogeneity based on the multiple modifiers identified during systematic review. These reasons include study format (randomized/prospective cohort/ retrospective cohort study), nationality, histology (degree of liver fibrosis), follow-up duration, Newcastle-Ottawa scale, age, and the regimen of the treatment (IFN, IFN with RBV, PegIFN with or without RBV). The follow-up duration of each study was categorized as long-term ( $\geq 5$ years) or short-term $(<5$ years).

\section{Statistics}

Comprehensive Meta-Analysis software (version 3, Biostat; Borenstein M, Hedges L, Higgins J and Rothstein $\mathrm{H}$. Englewood, NJ, USA) was used for this meta-analysis. We calculated the ORs with $95 \%$ confidence intervals (CIs) using $2 \times 2$ tables from the original articles to evaluate the efficacy of antiviral treatment between the treatment and control groups, or the SVR and no SVR groups whenever possible. Heterogeneity was determined using the $I^{2}$ test developed by Higgins, which measures the percentage of total variation across studies [8]. $I^{2}$ was calculated as follows: $I^{2}(\%)=100 \times(\mathrm{Q}-\mathrm{df}) / \mathrm{Q}$, where $\mathrm{Q}$ is Cochrane's heterogeneity statistic and $\mathrm{df}$ signifies the degree of freedom. Negative values for $I^{2}$ were set to zero, and an $I^{2}$ value over 50\% was considered to be of substantial heterogeneity (range: 0-100\%) [9]. Pooled-effect sizes with $95 \%$ CIs were calculated using a random effects model and the method of DerSimonian and Laird due to methodological heterogeneity [10]. These results were confirmed by the $I^{2}$ test. Significance was set at $p=0.05$. Publication bias was evaluated using Begg's funnel plot, Egger's test of the intercept, Begg and Mazumdar's rank correlation test, and Duval and Tweedie's trim and fill method [11-15].

\section{Results}

\section{Identification of relevant studies}

Figure 1 presents a flow diagram of how relevant studies were identified. In total, 36,421 articles were identified by a search of 3 databases. In all, 7451 duplicate studies and an additional 28,481 studies were excluded during the initial screening through a review of the titles and abstracts. The full texts of the remaining 489 studies were then thoroughly reviewed. Among these studies, 431 articles were excluded from the final analysis. The reasons for study exclusion during the final review were as follows: review article $(n=12)$, incomplete data $(n=7)$, not meeting the inclusion criteria $(n=409)$, or abstract only study $(n=3)$. The remaining 58 studies [4 randomized controlled studies (RCTs), 15 prospective cohort, and 40 retrospective cohort studies] were included in the final analysis.

\section{Characteristics of included studies}

In each study topic, about 13-35 studies were enrolled. In terms of the study format, RCTs, prospective and retrospective cohort studies were mixed. The number of Western population-based studies and the number of Asian population-based studies were evenly distributed. The age of enrolled patients ranged from 37 to 64 years (median). The follow-up duration ranged from 32 months (mean) to 11.5 years (median). Most of the studies used IFN-based regimens with or without RBV in topic 1, 2 and 3. However, a PegIFN-based regimen and IFN-based regimens were evenly distributed in topic 4,5 , and 6. Underlying histology of liver was variable, but some studies exclusively assessing liver cirrhosis patients were included. The detailed characteristics of the included studies are described in Tables 2, 3, 4, 5, and 6 .

\section{Methodological quality}

The methodological quality of cohort study is described in the Table 3, 4, 5 and 6 . This feature was evaluated as modifiers in each analysis. The methodological quality of RCT is described in Additional file 1: Appendix 1. Given the similar methodological quality among RCTs, sensitivity analysis or subgroup analyses based on the methodological quality in RCTs were not performed.

\section{Efficacy of antiviral treatment on the development of HCC in chronic hepatitis $C$ patients}

The overall efficacy of antiviral treatment on the development of HCC exhibited an OR of 0.392 (95\% CI: 0.2750.557, $p<0.001$ ) in a random effect model analysis (Fig. 2). 


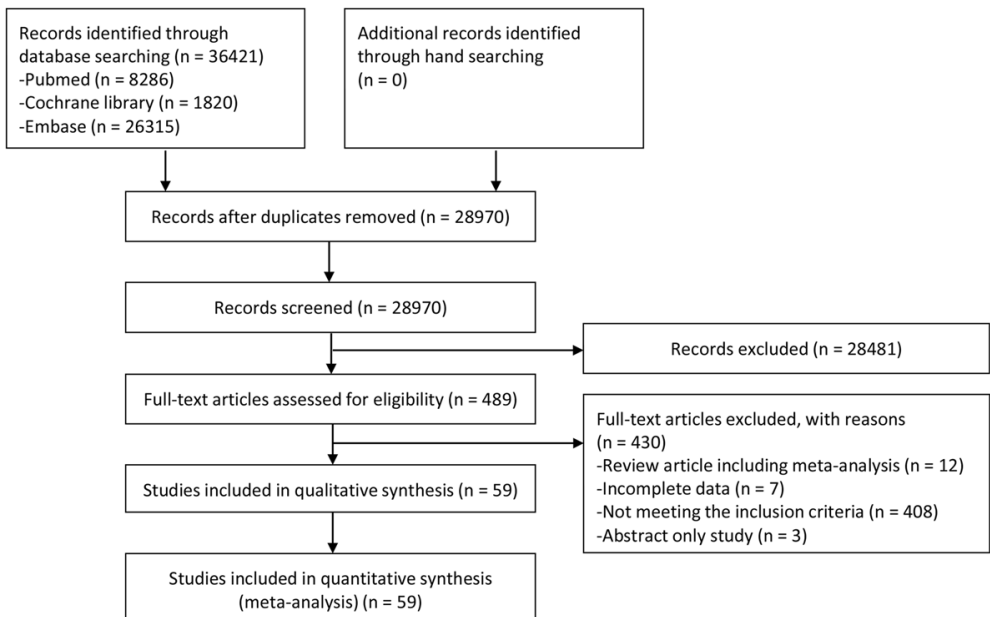

Fig. 1 Flow diagram for identification of relevant studies

The funnel plot showed asymmetry on the right lower quadrant area (Additional file 1: Appendix Figure S2). However, the Egger's test revealed an intercept of -2.131 (95\% CI: $-4.81-0.54$, t-value: 1.64 , df: $23, p=0.11$ (2tailed)). The rank correlation test also showed a Kendall's tau of -0.19 with a continuity correction $(p=0.17)$. The trim and fill method indicated that no study was trimmed. Overall, there was no evidence of publication bias.

A cumulative meta-analysis of enrolled studies based on publication year showed no specific time trend (Additional file 1: Appendix 3). A cumulative metaanalysis based on effect size showed no small study bias (Additional file 1: Appendix 4). One study removed meta-analysis revealed a stable feature (Additional file 1: Appendix 5). Overall, the sensitivity meta-analyses revealed robust results.

Methodological quality of Newcastle-Ottawa scale potentially explained heterogeneity in meta-ANOVA tests $(p=0.027)$ (Additional file 1: Appendix 6). A metaregression revealed a Newcastle-Ottawa scale score of 8 for the reason of heterogeneity $(p=0.027)$ (Additional file 2: Table S1). After excluding 10 studies (NewcastleOttawa scale 8), no covariates explained heterogeneity in meta-regression tests. Therefore, methodological quality was the reason of heterogeneity in this analysis.

\section{Efficacy of antiviral treatment on All-cause mortality in patients with chronic hepatitis $C$}

The overall efficacy of antiviral treatment on all-cause mortality revealed an OR of 0.380 (95\% CI: 0.295-0.489, $p<0.001$ ) in a random effect model analysis (Fig. 3). The funnel plot showed asymmetry on the right lower quadrant area (Additional file 1: Appendix 7). However, the Egger's test revealed an intercept of 0.266 (95\% CI: $-2.010-2.542$, t-value: 0.25 , df: $15, p=0.81$ (2-tailed)). The rank correlation test also showed a Kendall's tau of
0.04 with a continuity correction $(p=0.84)$. The trim and fill method indicated that 1 study was trimmed. After excluding the study by Testino et al. [16] located on the left lower quadrant in funnel plot, the OR was 0.385 (95\% CI: $0.298-0.496, p<0.001$ ). Overall, the impact of bias was minimal.

A cumulative meta-analysis of enrolled studies based on publication year showed no specific time trend (Additional file 1: Appendix 8). A cumulative meta-analysis based on effect size showed no small study bias (Additional file 1: Appendix 9). One study removed meta-analysis revealed a stable feature (Additional file 1: Appendix 10). Overall, the sensitivity meta-analyses revealed robust results.

Meta-ANOVA or meta-regression showed no specific modifier for the reason of heterogeneity (Additional file 1: Appendix 11) (Additional file 2: Table S2). Overall, no covariates were found to be explaining heterogeneity in this meta-analysis.

\section{Efficacy of antiviral treatment on liver-specific mortality in chronic hepatitis C patients}

The overall efficacy of antiviral treatment on liverspecific mortality exhibited an OR of 0.363 (95\% CI: $0.260-0.508, p<0.001$ ) in a random effect model analysis (Additional file 1: Appendix 12). The funnel plot showed symmetry (Additional file 1: Appendix 13). However, the Egger's test revealed that intercept was 3.06 (95\% CI: $0.295-5.831, \mathrm{t}$-value: 2.43 , df: $11, p=0.03$ (2-tailed)). The rank correlation test showed a Kendall's tau of 0.28 with a continuity correction $(p=0.20)$. The trim and fill method indicated that no study was trimmed. After excluding an outlier (study by Kasahara A et al. [17]) located on the left upper quadrant area in funnel plot, the OR was 0.398 (95\% CI: 0.314-0.504, $p<0.001$ ). Overall, the impact of bias was minimal. 


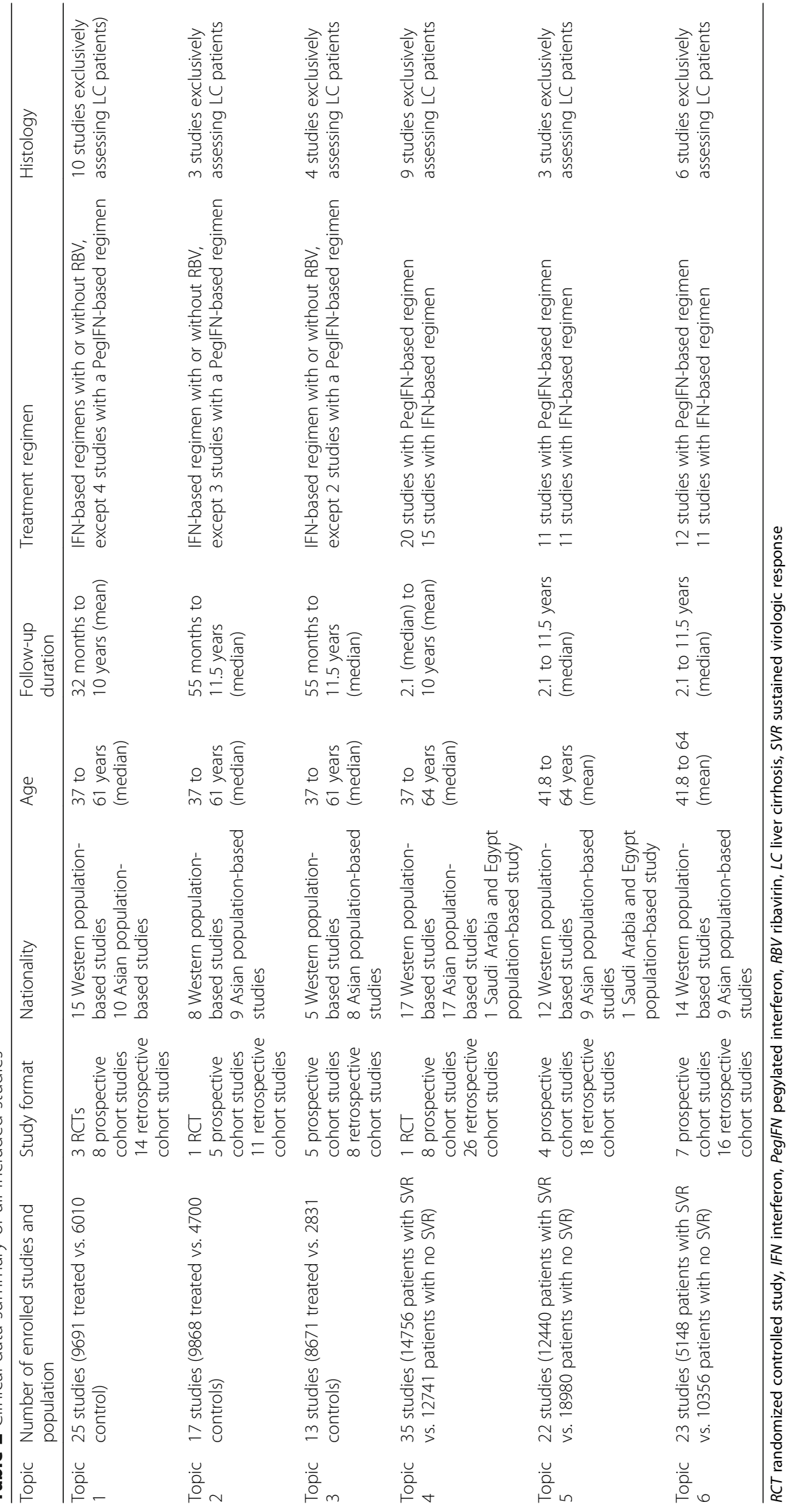




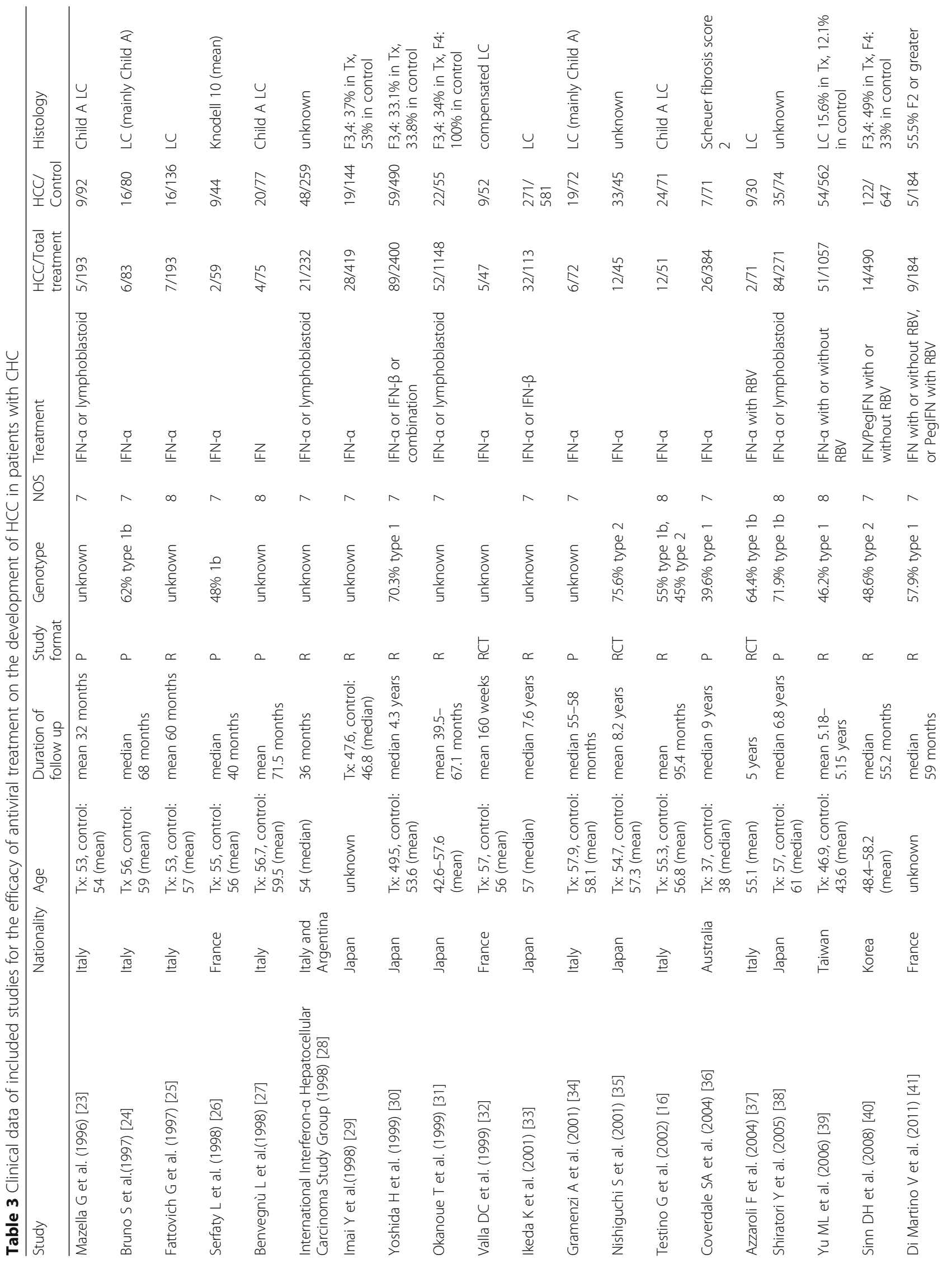




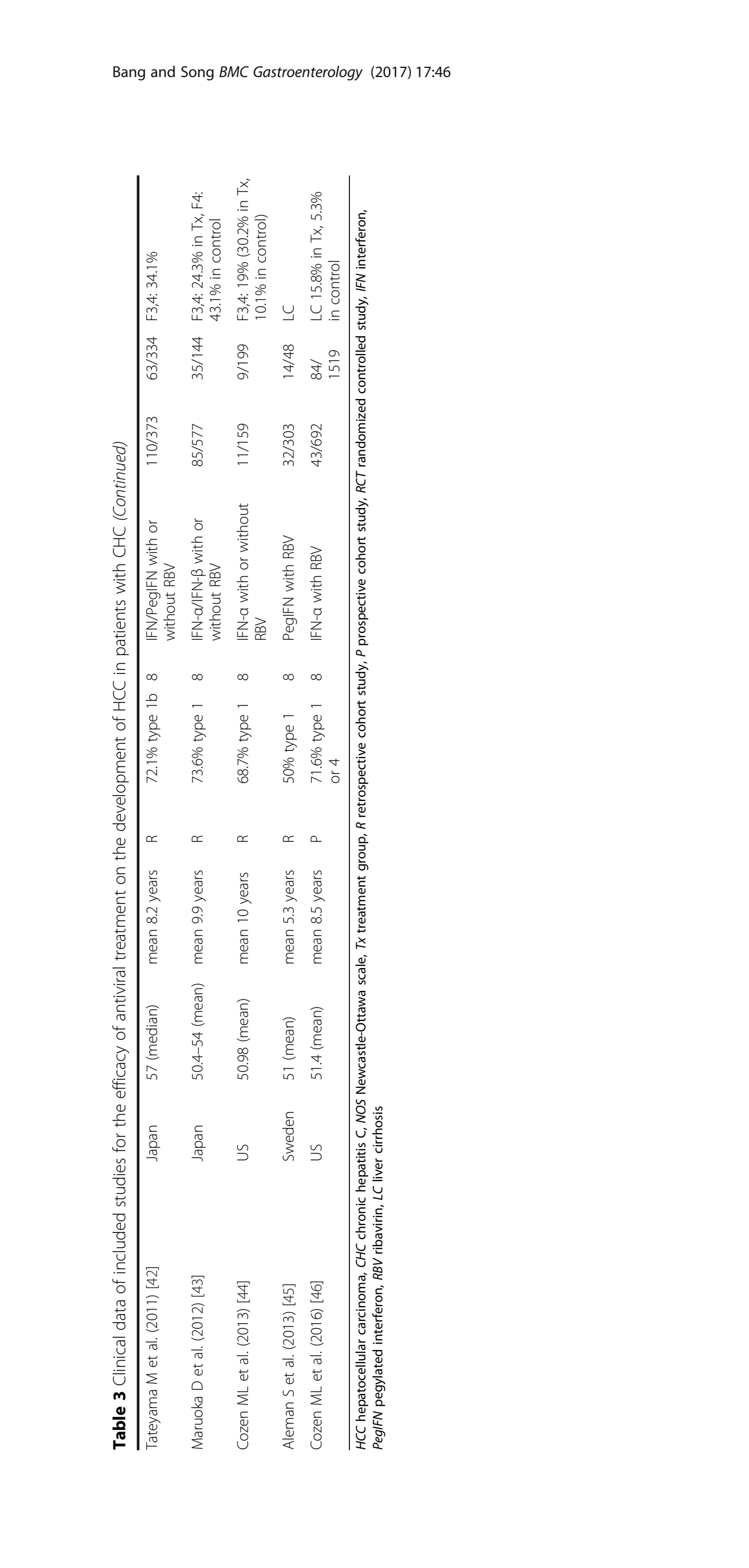




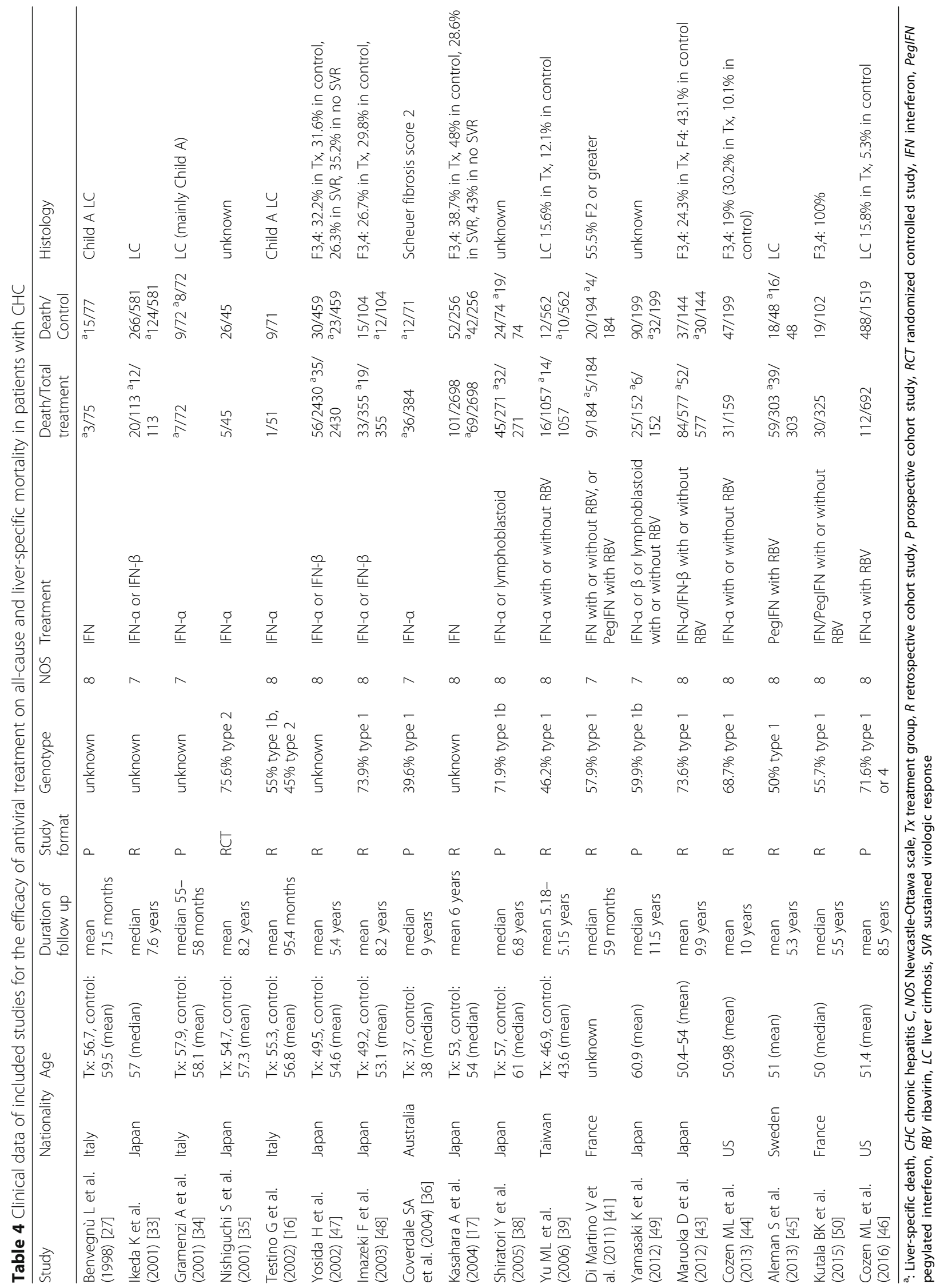




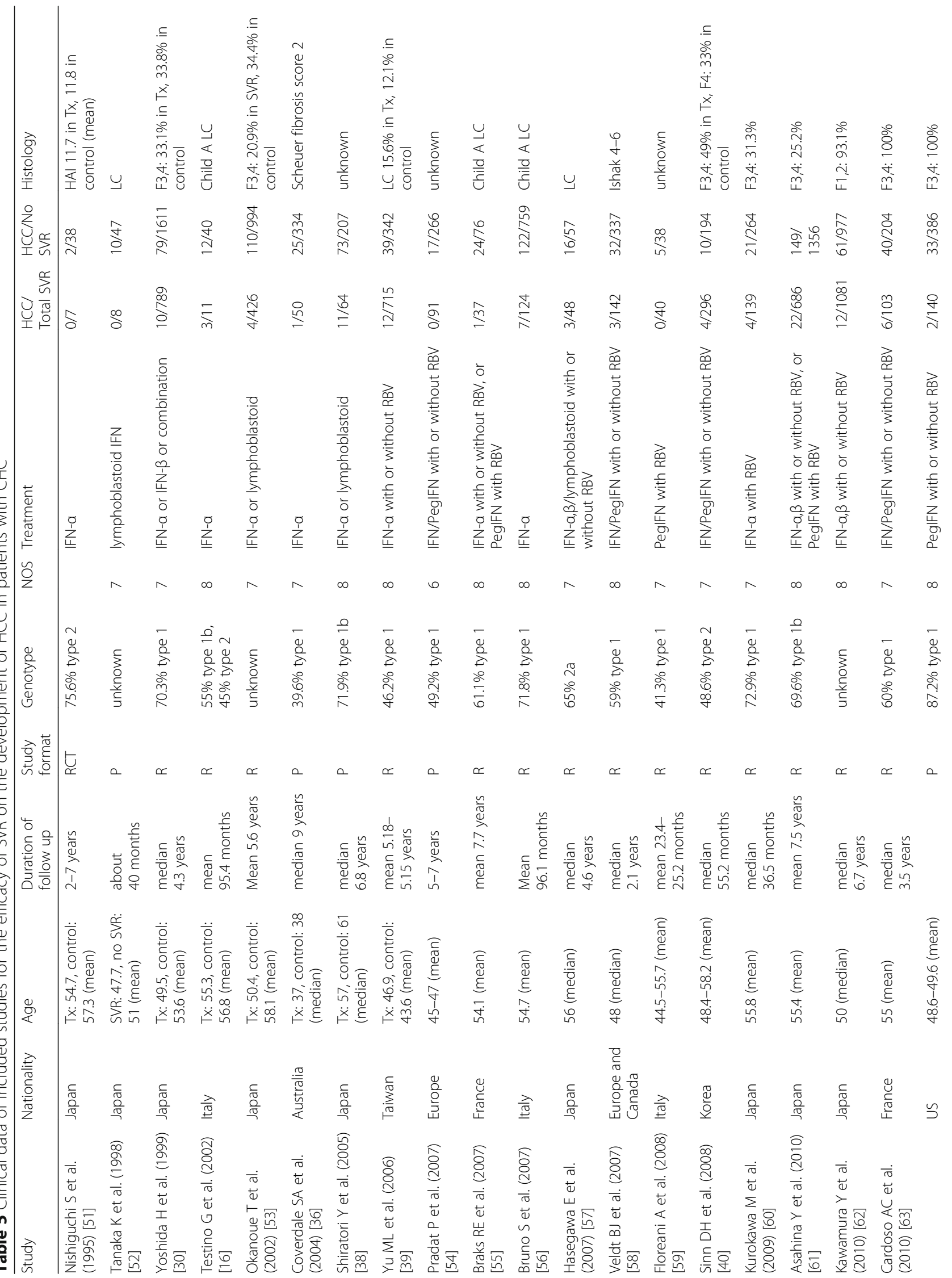




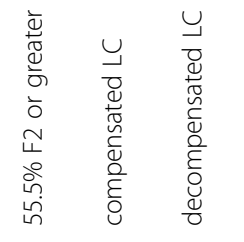

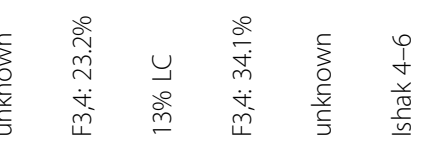
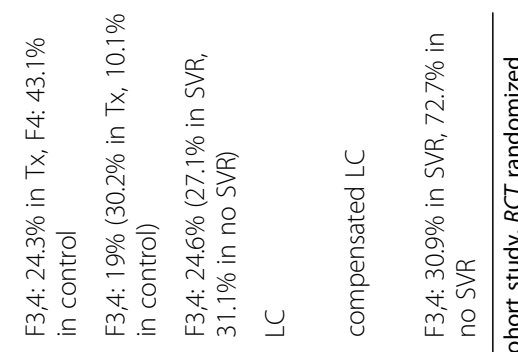

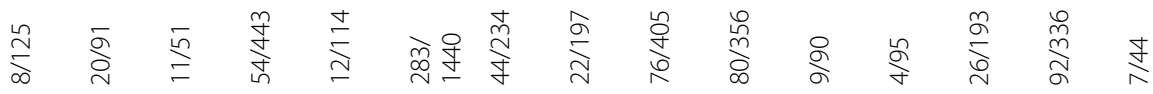

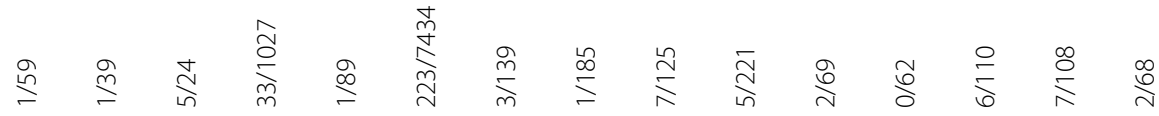

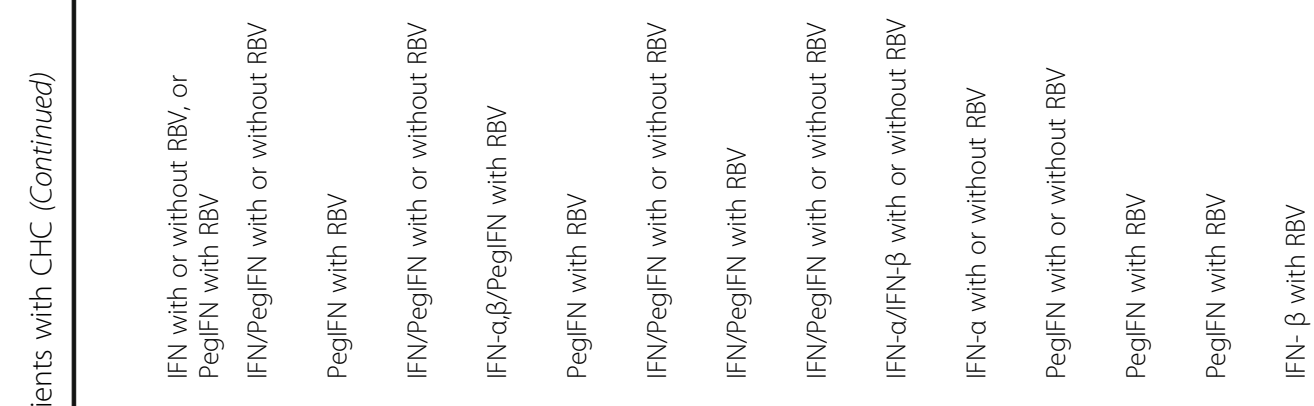

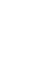

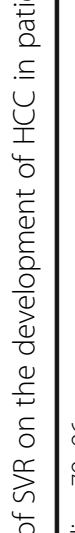

$\wedge \wedge \wedge \wedge \wedge \quad \infty \quad \infty \quad \infty$

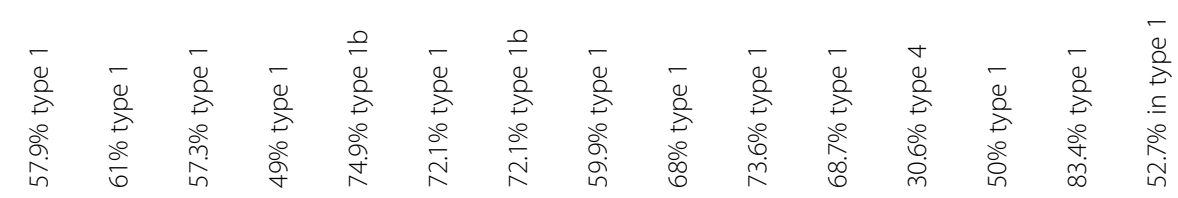

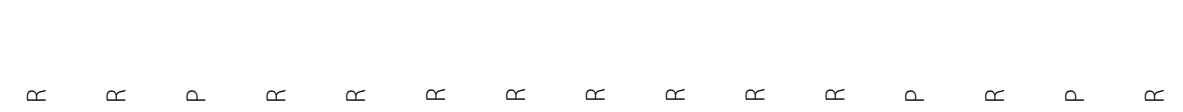

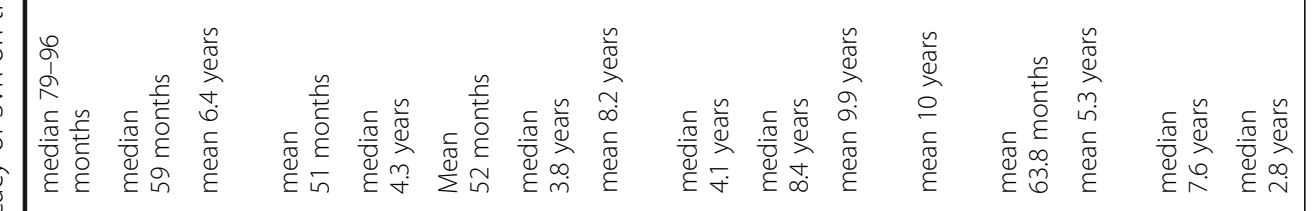

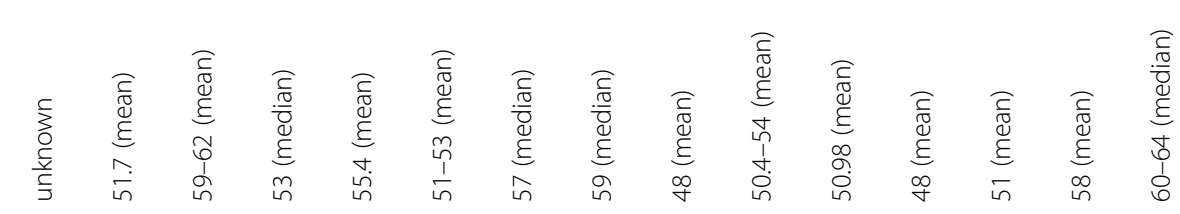

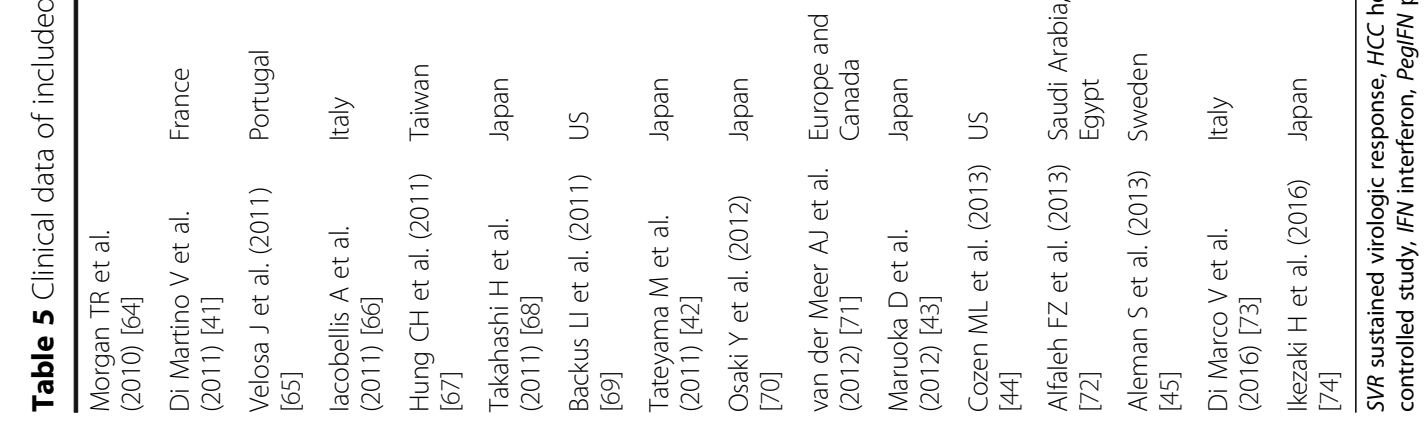




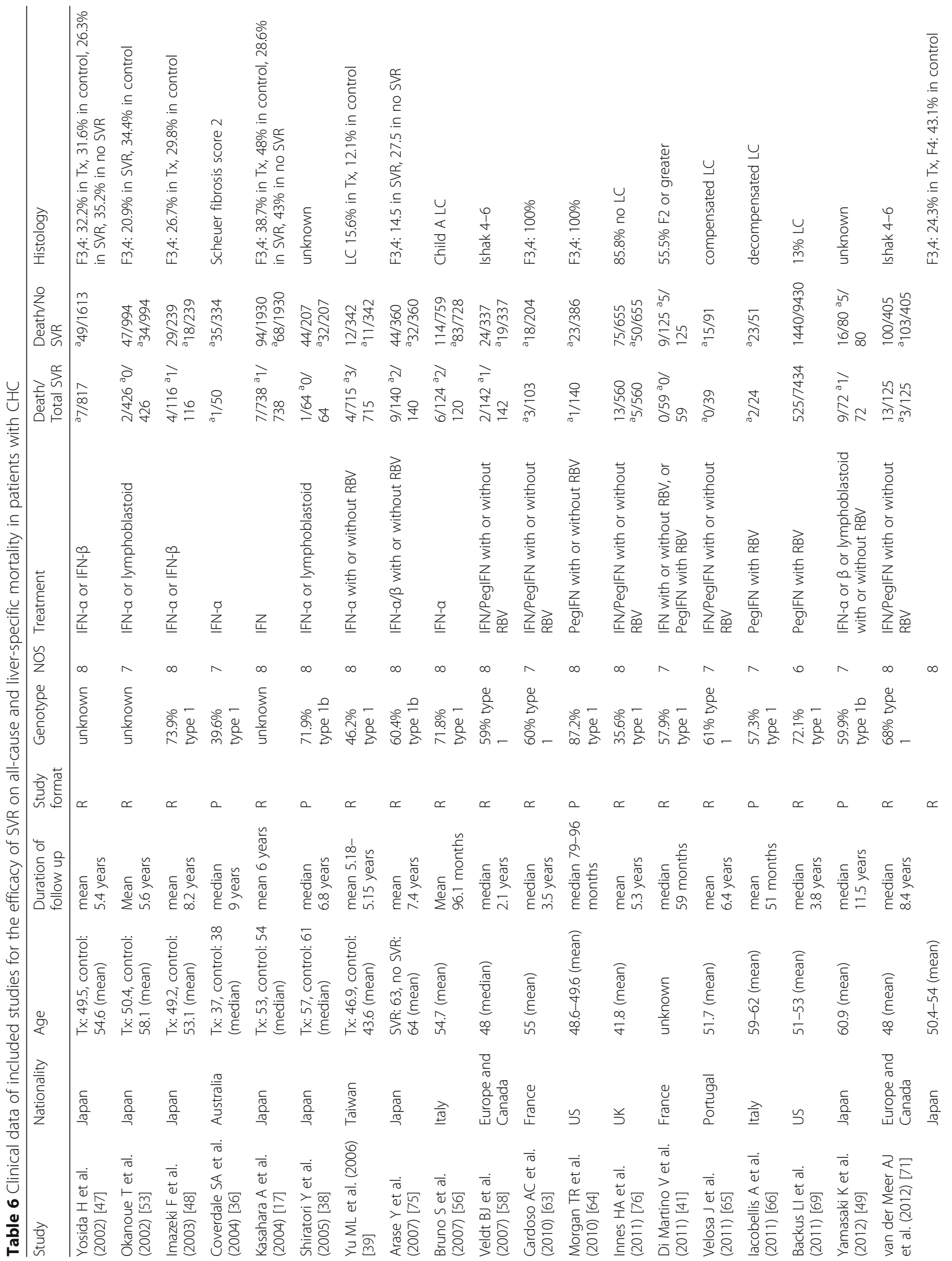




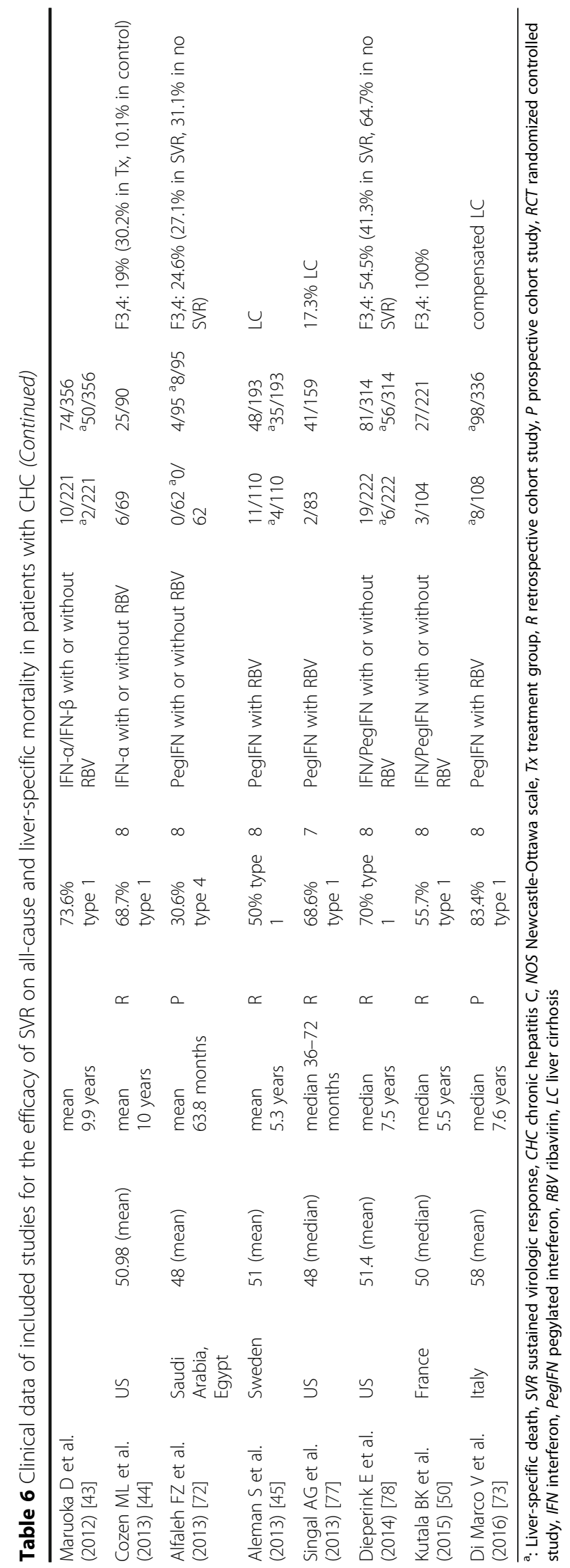




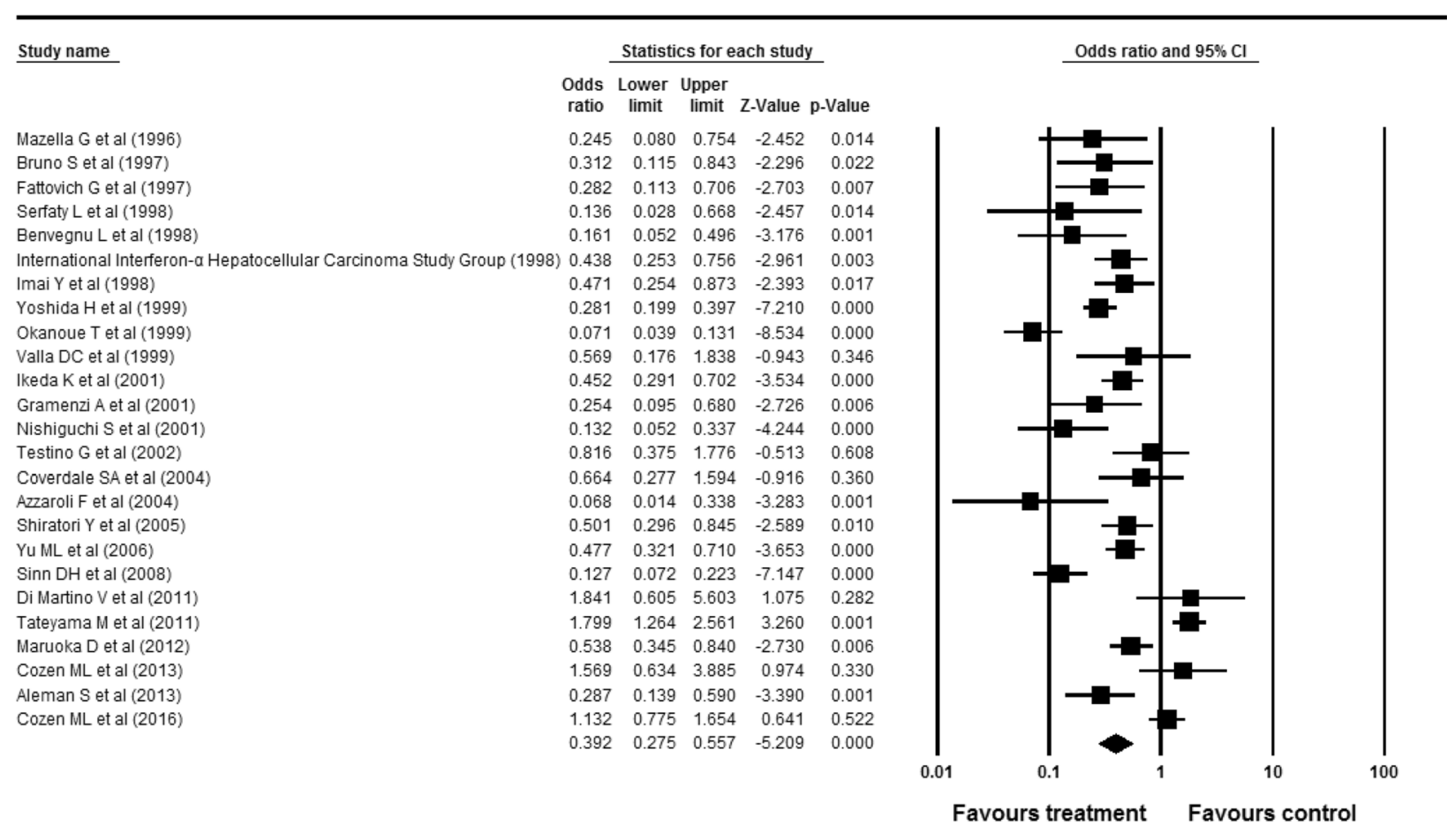

Heterogeneity: $X^{2}=182.934, \mathrm{df}=24(P<0.001) ; P=86.881 \%$

Test for overall effect: $Z=-5.209(P<0.001)$

Fig. 2 Efficacy of antiviral treatment on the development of HCC in patients with CHC. The size of each square is proportional to the study's weight. Diamond is the summary estimate from the pooled studies (random effect model). HCC, hepatocellular carcinoma; CHC, chronic hepatitis C

A cumulative meta-analysis of enrolled studies based on publication year showed no specific time trend (Additional file 1: Appendix 14). A cumulative meta-analysis based on effect size showed no small study bias (Additional file 1: Appendix 15). One study removed meta-analysis revealed a stable feature (Additional file 1: Appendix 16). Overall, the sensitivity meta-analyses showed robust results.

A meta-ANOVA indicated that follow-up duration ( $p=$ $0.036)$ and methodological quality $(p=0.029)$ were suspicious for the reason of heterogeneity (Additional file 1: Appendix 17). A meta-regression indicated that follow-up duration $(p=0.036)$ and Newcastle-Ottawa scale score of 8 $(p=0.029)$ explained the heterogeneity (Additional file 2: Table S3). After excluding 2 studies (short-term follow-up duration), no covariates explained heterogeneity in metaregression tests. After excluding 7 studies (NewcastleOttawa scale 8), no covariates explained heterogeneity in meta-regression tests. Therefore, follow-up duration and methodological quality were the reasons of heterogeneity in this analysis.

\section{Efficacy of SVR on the development of HCC in patients} with chronic hepatitis $C$

The overall efficacy of SVR on the development of HCC exhibited an OR of 0.203 (95\% CI: 0.164-0.251, $p<0.001$ ) in a random effect model analysis (Fig. 4). The funnel plot showed symmetry (Additional file 1: Appendix 18). The Egger's test showed that intercept was 0.56 (95\% CI: -0.099-1.217, t-value: 1.73, df: 33, $p=0.09$ (2-tailed)). The rank correlation test showed a Kendall's tau of -0.17 with a continuity correction $(p=0.16)$. The trim and fill method indicated that no study was trimmed. Overall, there was no evidence of publication bias.

A cumulative meta-analysis of enrolled studies based on publication year showed no specific time trend (Additional file 1: Appendix 19). A cumulative meta-analysis based on effect size showed no small study bias (Additional file 1: Appendix 20). One study removed meta-analysis showed a stable feature (Additional file 1: Appendix 21). Overall, the sensitivity meta-analyses revealed robust results.

Meta-ANOVA or meta-regression identified no specific modifier for the reason of heterogeneity (Additional file 1: Appendix 22) (Additional file 2: Table S4). Overall, no covariates explained heterogeneity.

\section{Efficacy of SVR on all-cause mortality in patients with chronic hepatitis $\mathbf{C}$}

The overall efficacy of SVR on all-cause mortality revealed an OR of 0.255 (95\% CI: $0.199-0.326, p<0.001$ ) in a random effect model analysis (Fig. 5). The funnel 


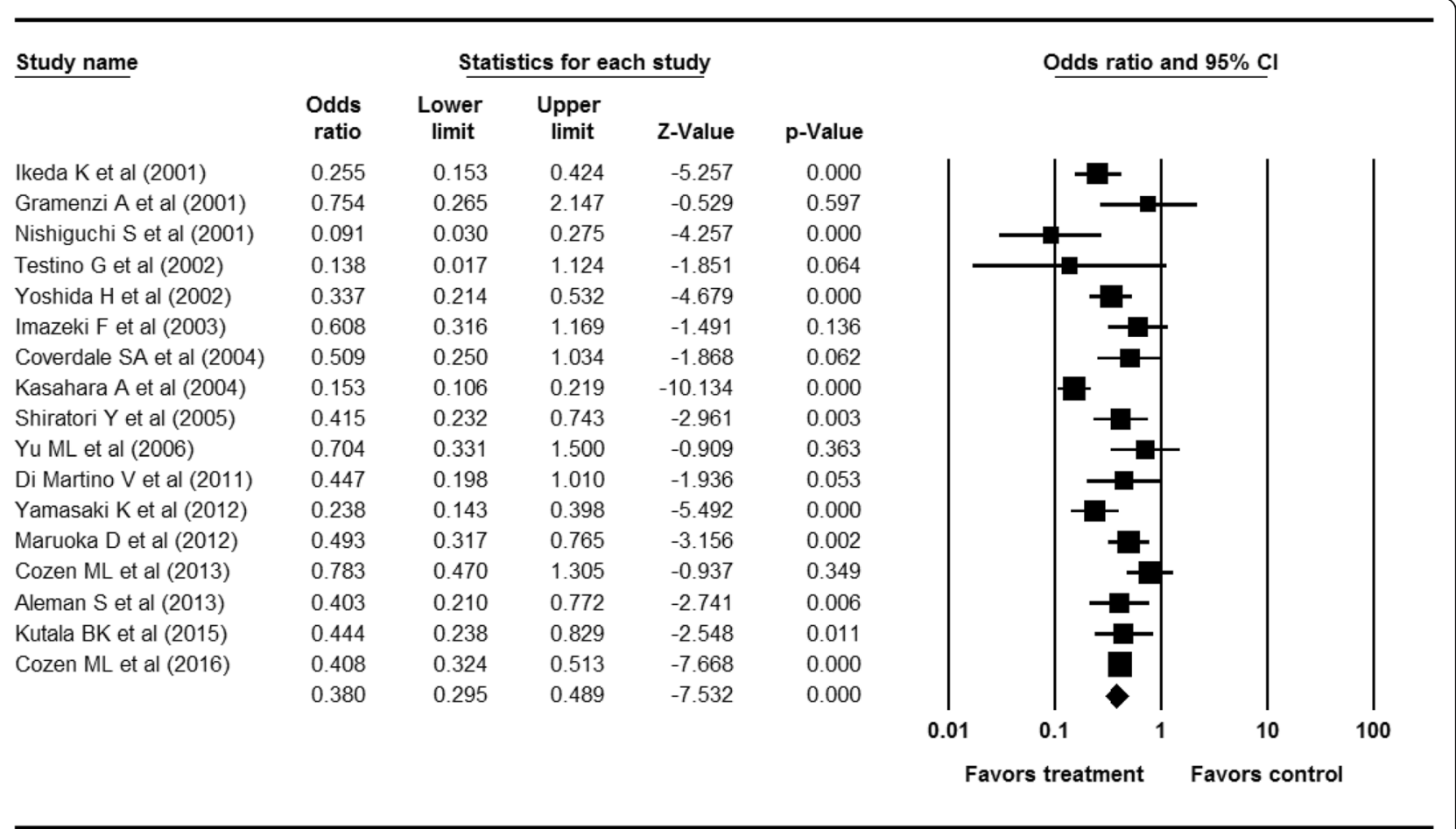

Heterogeneity: $X^{2}=53.796, \mathrm{df}=16(P<0.001) ; P^{2}=70.258 \%$

Test for overall effect: $Z=-7.532(P<0.001)$

Fig. 3 Efficacy of antiviral treatment on all-cause mortality in patients with CHC. The size of each square is proportional to the study's weight. Diamond is the summary estimate from the pooled studies (random effect model). CHC, chronic hepatitis C

plot showed asymmetry on the right lower quadrant area (Additional file 1: Appendix 23). The Egger's test showed that the intercept was $-1.44 \quad(95 \%$ CI: $-1.921--0.949$, t-value: 6.16, df: $20, p<0.001$ (2tailed)). The rank correlation test showed a Kendall's tau of -0.23 with a continuity correction $(p=0.14)$. The trim and fill method indicated 11 studies were trimmed. Overall, there was evidence of publication bias.

A cumulative meta-analysis of enrolled studies based on publication year showed no specific time trend (Additional file 1: Appendix 24). A cumulative meta-analysis based on effect size showed no small study bias (Additional file 1: Appendix 25). One study removed metaanalysis revealed a stable feature (Additional file 1: Appendix 26). Overall, the sensitivity meta-analyses showed robust results.

Meta-ANOVA indicated that methodological quality potentially explained heterogeneity $(p=0.030)$ (Additional file 1: Appendix 27). Meta-regression revealed a Newcastle-Ottawa scale score of 8 for the reason of heterogeneity (Additional file 2: Table S5). After excluding 16 studies (Newcastle-Ottawa scale 8), no covariates explained heterogeneity in meta-regression tests. Therefore, methodological quality was the reasons of heterogeneity in this analysis.

\section{Efficacy of SVR on liver-specific mortality in chronic hepatitis $\mathrm{C}$ patients}

The overall efficacy of SVR on liver-specific mortality exhibited an OR of 0.126 (95\% CI: 0.094-0.169, $p<0.001)$ in a random effect model analysis (Additional file 1: Appendix 28). The funnel plot showed asymmetry on the right lower quadrant area (Additional file 1: Appendix 29). The Egger's test indicated that intercept was -0.77 (95\% CI: $-1.473--0.057$, t-value: 2.25 , df: $21, p=0.036$ (2-tailed)). The rank correlation test revealed a Kendall's tau of -0.19 with a continuity correction $(p=0.20)$. The trim and fill method showed 6 studies were trimmed. Overall, there was evidence of publication bias.

A cumulative meta-analysis of enrolled studies based on publication year showed no specific time trend (Additional file 1: Appendix 30). A cumulative metaanalysis based on effect size showed no small study bias (Additional file 1: Appendix 31). One study removed meta-analysis revealed a stable feature (Additional file 1: Appendix 32). Overall, the sensitivity meta-analyses showed robust results.

Meta-ANOVA or meta-regression revealed no specific modifier for the reason of heterogeneity (Additional file 1: Appendix 33) (Additional file 2: Table S6). Overall, no covariates explained heterogeneity. 
Odds ratio and $95 \% \mathrm{Cl}$

Odds Lower Upper

ratio limit limit $Z$-Value $p$-Value

$\begin{array}{llllll}\text { Nishiguchi S et sl (1995) } & 0.973 & 0.042 & 22.407 & -0.017 & 0.987\end{array}$ $\begin{array}{lllllll}\text { Tanaka K et al }(1998) & 0.210 & 0.011 & 3.947 & -1.043 & 0.297\end{array}$

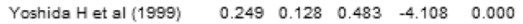
$\begin{array}{lllllll}\text { Testino } G \text { et al (2002) } & 0.875 & 0.197 & 3.880 & -0.178 & 0.881\end{array}$ Ckanoue T et al (2002) $0.070 \quad 0.028 \quad 0.208 \quad-5.024 \quad 0.000$ $\begin{array}{lllllll}\text { Yu ML et } \mathrm{al}(2008) & 0.133 & 0.068 & 0.257 & -5.992 & 0.000\end{array}$ Pradat $P$ et al $(2007) \quad \begin{array}{lllllll}0.078 & 0.005 & 1.309 & -1.773 & 0.078\end{array}$ $\begin{array}{lllllll}\text { Braks RE et al (2007) } \quad 0.060 & 0.008 & 0.485 & -2.893 & 0.007\end{array}$ $\begin{array}{lllllll}\text { Bruno S et al (2007) } & 0.312 & 0.142 & 0.688 & -2.898 & 0.004\end{array}$ $\begin{array}{llllllll}\text { Hasegawg E et al (2007) } & 0.171 & 0.046 & 0.629 & -2.657 & 0.008\end{array}$ Veldt Bu et al (2007) Sinn DH et al (2008) $\quad \begin{array}{llllll}0.252 & 0.078 & 0.815 & -2.300 & 0.021\end{array}$

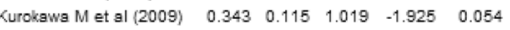

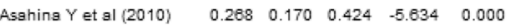

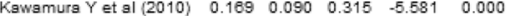

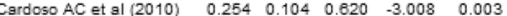

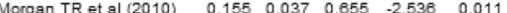
Velosa J et al (2011) $\quad \begin{array}{lllllll}0.093 & 0.012 & 0.723 & -2.270 & 0.023\end{array}$ $\begin{array}{lllllll} & \text { lacobellis A et al (2011) } & 0.957 & 0.291 & 3.145 & -0.073 & 0.942\end{array}$ Hung $\mathrm{CH}$ et al (2011) $\quad \begin{array}{llllll}0.239 & 0.153 & 0.375 & -6.250 & 0.000\end{array}$ Takghashi H et al (2011) $\quad 0.097 \quad 0.012 \quad 0.758 \quad-2.224 \quad 0.026$ Badus Ll et al (2011) $\quad \begin{array}{lllllll}0.126 & 0.105 & 0.152 & -21.774 & 0.000\end{array}$ $\begin{array}{llllllll}\text { Tsteysms M et al (2011) } & 0.095 & 0.029 & 0.313 & -3.872 & 0.000\end{array}$ Togki Yet al (2012) $0.0430 .008 \quad 0.324 \quad-3.058 \quad 0.002$

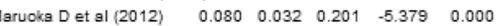
Cozen ML et al (2013) $\quad 0.269 \quad 0.056 \quad 1.286 \quad-1.645 \quad 0.100$ Alfaleh FZ et al (2013) $\quad 0.163 \quad 0.009 \quad 3.075 \quad-1.211 \quad 0.226$ Aleman S et al (2013) $\quad \begin{array}{llllll}0.371 & 0.148 & 0.931 & -2.113 & 0.035\end{array}$ Di Marco V et al (2016) $\quad \begin{array}{lllllll}0.184 & 0.082 & 0.410 & -4.138 & 0.000\end{array}$ lkezaki $\mathrm{H}$ et al $(2018) \quad \begin{array}{lllllll}0.180 & 0.032 & 0.811 & -2.213 & 0.027\end{array}$ $\begin{array}{lllll}0.203 & 0.184 & 0.251 & -14.759 & 0.000\end{array}$

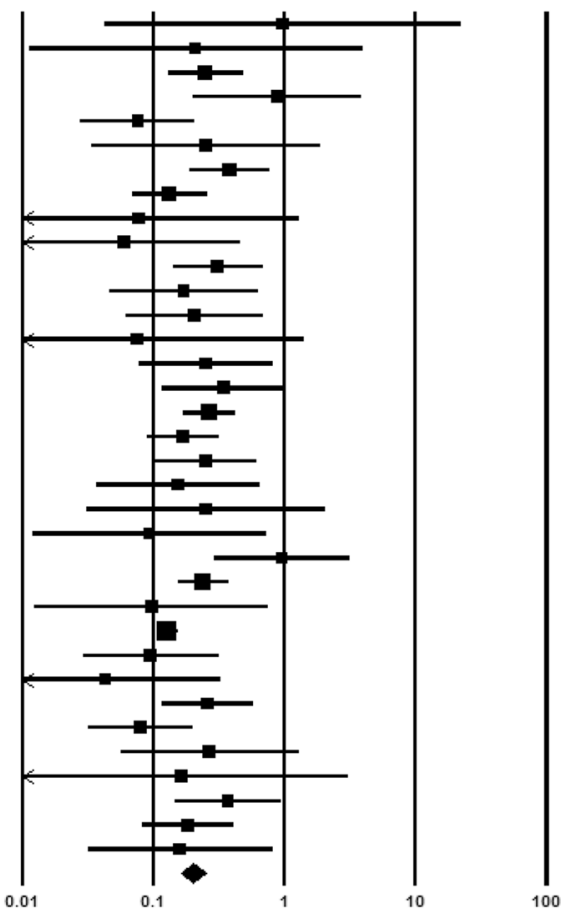

Favours SVR Favours no SVR

Heterogeneity: $X^{2}=56.031, \mathrm{df}=34(P=0.010) ; R=39.319 \%$

Test for overall effect: $Z=-14.759(P<0.001)$

Fig. 4 Efficacy of SVR on the development of HCC in patients with CHC. The size of each square is proportional to the study's weight. Diamond is the summary estimate from the pooled studies (random effect model). SVR, sustained virologic response; HCC, hepatocellular carcinoma; CHC, chronic hepatitis C

The results of meta-regression analyses for each topic are summarized in Table 7.

\section{Discussion}

This meta-analyses confirmed the long-term efficacy of antiviral treatment in terms of prevention of HCC and reduction in all-cause and liver-specific mortality in patients with chronic HCV infection. This long-term efficacy was also intensified when SVR was achieved. Clinical outcomes regarding the efficacy of antiviral therapy in $\mathrm{CHC}$ patients have been continuously investigated by previous studies with a small number of patients or short-term follow-up duration. The reasons for performing this meta-analysis were a persistent risk of HCC even after attainment of SVR and a lack of sufficient data regarding long-term efficacy [18]. Persistent lowlevel of viremia and dysplastic hepatocyte regeneration are representative grounds for persistent risk of $\mathrm{HCC}$ after antiviral treatment $[19,20]$. Interestingly, a recent meta-analysis revealed that IFN nonresponders exhibited a decreased risk of $\mathrm{HCC}$ recurrence after curative treatment of HCC, compared with no treatment patients, thus indicating that reduced necroinflammation and an inhibition of hepatic fibrosis progression prevent the development of HCC [21]. This results is consistent with that of our study and emphasized the importance of screening strategy of chronic hepatitis $\mathrm{C}$.

Early antiviral treatment before progression to advanced fibrosis or cirrhosis is associated with an increasing probability of achieving SVR [22]. However, an indolent course of chronic hepatitis $\mathrm{C}$ makes it difficult for early diagnosis and treatment. Authors have revealed that favorable antiviral efficacy persists in all patients with chronic hepatitis $C$, regardless of histology. This result was also confirmed by a previous study indicating favorable antiviral efficacy even in patients with LC [18]. Considering the advanced fibrosis or cirrhosis is the sequelae of long-standing inflammation of liver, our study confirmed antiviral treatment is still valid in the late course of chronic hepatitis C. Although histology was 


\begin{tabular}{lrrrrr}
\hline Study name & \multicolumn{5}{c}{ Statistics for each study } \\
\cline { 3 - 6 } & $\begin{array}{c}\text { Odds } \\
\text { ratio }\end{array}$ & $\begin{array}{c}\text { Lower } \\
\text { limit }\end{array}$ & $\begin{array}{l}\text { Upper } \\
\text { limit }\end{array}$ & Z-Value & p-Value \\
Yoshida H et al (2002) & 0.276 & 0.124 & 0.612 & -3.169 & 0.002 \\
Okanoue T et al (2002) & 0.095 & 0.023 & 0.393 & -3.249 & 0.001 \\
Imazeki F et al (2003) & 0.259 & 0.089 & 0.754 & -2.477 & 0.013 \\
Kasahara A et al (2004) & 0.187 & 0.086 & 0.405 & -4.253 & 0.000 \\
Shiratori Y et al (2005) & 0.059 & 0.008 & 0.436 & -2.772 & 0.006 \\
Yu ML et al (2006) & 0.155 & 0.050 & 0.483 & -3.211 & 0.001 \\
Arase Y et al (2007) & 0.493 & 0.234 & 1.040 & -1.857 & 0.063 \\
Braks RE et al (2007) & 0.037 & 0.002 & 0.626 & -2.283 & 0.022 \\
Bruno S et al (2007) & 0.288 & 0.124 & 0.669 & -2.893 & 0.004 \\
Veldt BJ et al (2007) & 0.186 & 0.043 & 0.799 & -2.262 & 0.024 \\
Innes HA et al (2011) & 0.184 & 0.101 & 0.335 & -5.531 & 0.000 \\
Di Martino V et al (2011) & 0.103 & 0.006 & 1.801 & -1.557 & 0.120 \\
Backus LI et al (2011) & 0.422 & 0.380 & 0.468 & -16.123 & 0.000 \\
Yamasaki K et al (2012) & 0.571 & 0.235 & 1.388 & -1.236 & 0.217 \\
van der Meer AJ et al (2012) & 0.354 & 0.191 & 0.656 & -3.298 & 0.001 \\
Maruoka D et al (2012) & 0.181 & 0.091 & 0.358 & -4.904 & 0.000 \\
Cozen ML et al (2013) & 0.248 & 0.095 & 0.644 & -2.862 & 0.004 \\
Alfaleh FZ et al (2013) & 0.082 & 0.005 & 1.453 & -1.705 & 0.088 \\
Aleman S et al (2013) & 0.336 & 0.166 & 0.678 & -3.043 & 0.002 \\
Singal AG et al (2013) & 0.071 & 0.017 & 0.302 & -3.581 & 0.000 \\
Dieperink E et al (2014) & 0.269 & 0.158 & 0.459 & -4.817 & 0.000 \\
Kutala BK et al (2015) & 0.213 & 0.063 & 0.721 & -2.488 & 0.013 \\
& 0.255 & 0.199 & 0.326 & -10.832 & 0.000
\end{tabular}

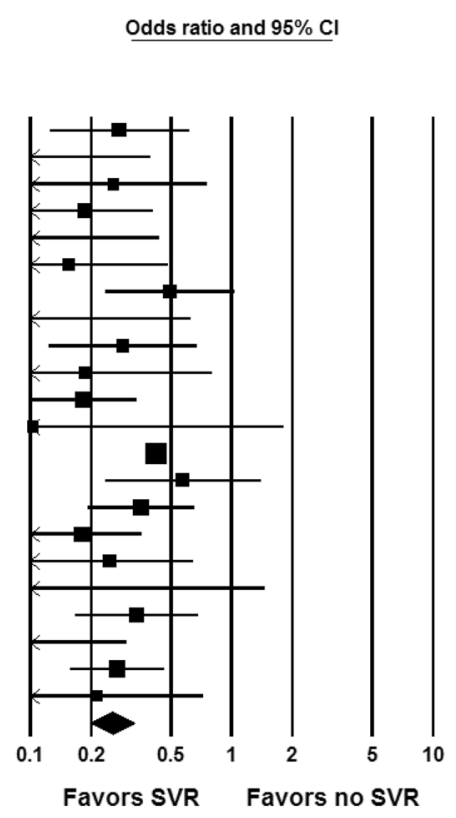

Heterogeneity: $X^{2}=43.249, \mathrm{df}=21(P=0.003) ; P^{2}=51.444 \%$

Test for overall effect: $Z=-10.832(P<0.001)$

Fig. 5 Efficacy of SVR on all-cause mortality in patients with CHC. The size of each square is proportional to the study's weight. Diamond is the summary estimate from the pooled studies (random effect model). SVR, sustained virologic response; CHC, chronic hepatitis C

not a significant modifier in our meta-analysis, all of the included studies have substantially heterogeneous populations regarding the degree of fibrosis or cirrhosis of the liver. This finding was commonly detected in a previous meta-analysis [18]. However, considering the expanding treatment indication, including decompensated LC by the advent of direct-acting antiviral agents, histology is not expected to affect the long-term efficacy of antiviral treatment in the near future.

Despite the favorable efficacy of antiviral treatment, 2 modifiers associated with heterogeneity were identified in the meta-ANOVA and meta-regression analyses. Studies with Newcastle-Ottawa scale of 8 were modifier in the analysis of association between antiviral treatment and the development of HCC (Additional file 2: Table S1), in the analysis of association between antiviral treatment and the liver-specific mortality (Additional file 2: Table S3), and in the analysis of association between SVR and all-cause mortality (Additional file 2: Table S5). Studies with a short-term follow-up duration were also modifier in the analysis of association between antiviral treatment and liver-specific mortality (Additional file 2: Table S3). Although these modifiers were confirmed as not significantly affecting the results of main analyses, this finding indicated the need for more number of high-quality and longterm follow-up studies on this topic.

Publication bias was detected in 2 topics (topic 5 and 6). Sensitivity analyses including cumulative and one study removed meta-analyses were rigorously performed to find the small study effect associated with publication bias, and these analyses showed no small study effect. Overall, the impact of publication bias was minimal.

Table 7 Results of meta-regression analyses

\begin{tabular}{llll}
\hline Modifier & Coefficient & Standard error & $P$ value \\
\hline NOS (topic 1) & NOS 8: 1.203 & 0.565 & 0.033 \\
& NOS 7: 0.501 & 0.561 & 0.372 \\
Q: & & $0.24, \mathrm{df:} 2, P=0.027$ \\
Follow-up duration (topic 3) & 1.140 & 0.542 & 0.036 \\
NOS (topic 3) & NOS 8: -0.659 & 0.302 & 0.029 \\
NOS (topic 5) & NOS 8: -0.540 & 0.209 & 0.010 \\
& NOS 7: -0.544 & 0.322 & 0.091 \\
& & & Q: $7.03, \mathrm{df:}: 2, P=0.030$
\end{tabular}


This meta-analysis included the largest number of articles identified by a comprehensive literature search, and potential confounding modifiers were searched within each study whenever possible. Sensitivity analyses and meta-regression tests were performed to demonstrate robustness or identify the reason of heterogeneity. Despite the strengths, several limitations were detected during the systematic review. First, pretreatment predictive factors associated with the treatment response were not controlled or evaluated in these analyses, including pretreatment viral load, genotype, IL-28 $\beta$ polymorphism, and HBV or HIV coinfection. Direct-acting antiviral agents are expected to overcome these factors. Therefore, results of studies including these agents are expected in the near future. Second, the baseline characteristics of each enrolled study were not comparable between the treatment vs. no treatment groups, or the SVR vs. no SVR groups in some studies. This phenomenon was reflected in the evaluation of methodological quality and was confirmed to be a significant modifier associated with heterogeneity. Notably, difference by race or country including life style (obesity, consumption of alcohol or aflatoxin-contaminated foods, and chemical carcinogens exposure) was not appropriately investigated in our study. Considering the HCC is a heterogenous malignancy resulting from diverse causes of liver injury, different mechanisms or molecular pathways on the basis of country could be a cause of different treatment response. However, due to the heterogenous baseline characteristics including genotype and lacking of enough data about risk factors of HCC, the subgroup analyses by country could not present meaningful data. The limitations described above could be a cause of potential heterogeneity and bias. Therefore, studies controlling for various risk factors are needed to confirm these findings.

\section{Conclusion}

In conclusion, antiviral treatment for chronic hepatitis $\mathrm{C}$ showed improved outcome in the development of HCC and mortality, especially when SVR is achieved, although studies controlling for various risk factors of $\mathrm{HCC}$ and mortality are still lacking.

\section{Additional files}

Additional file 1: Contains 33 figures including assessment of methodological quality, funnel plots for publication bias, sensitivity analyses, and Meta-ANOVA. (DOC 24248 kb)

Additional file 2: Contains 6 tables including detailed meta-regression data of 6 study topics of this study. (DOC $79 \mathrm{~kb}$ )

\section{Abbreviations}

CHC: Chronic hepatitis C; Cl: Confidence interval; HCC: Hepatocellular carcinoma; HCV: Hepatitis C virus; IFN: Interferon; OR: Odds ratio; PeglFN: Pegylated interferon; RBV: Ribavirin; RCT: Randomized controlled studies; SVR: Sustained virologic response

\section{Acknowledgements}

Authors would like to appreciate Dr. Young Joo Yang's effort for helping manuscript searching and data filling up for this study.

\section{Funding}

There was no financial or grant support related to this article.

\section{Availability of data and materials}

Input data for the analyses are available from the corresponding author on request.

\section{Author's contributions}

CSB participated study concept, design, literature search, data abstraction, data analysis and manuscript writing. IHS participated study concept, design, data analysis and gave final approval for publication. All authors have read and approved the final version of this manuscript.

\section{Competing interests \\ None}

Consent for publication

Not applicable.

Ethics approval and consent to participate

Not applicable.

\section{Publisher's Note}

Springer Nature remains neutral with regard to jurisdictional claims in published maps and institutional affiliations.

\section{Author details}

${ }^{1}$ Department of Internal Medicine, Hallym University College of Medicine, Chuncheon, Republic of Korea. '2Division of Hepatology, Department of Internal Medicine, Dankook University College of Medicine, Cheonan, Korea, Republic of Korea.

Received: 14 January 2017 Accepted: 28 March 2017

Published online: 04 April 2017

\section{References}

1. AASLD/IDSA HCV Guidance Panel. Hepatitis C guidance: AASLD-IDSA recommendations for testing, managing, and treating adults infected with hepatitis C virus. Hepatology. 2015;62:932-54.

2. Swain MG, Lai M, Shiffman ML, Cooksley WG, Zeuzem S, Dieterich DT, Abergel A, Pessôa MG, Lin A, Tietz A, et al. A sustained virologic response is durable in patients with chronic hepatitis $C$ treated with peginterferon Alfa-2a and ribavirin. Gastroenterology. 2010;139:1593-601.

3. Martinot-Peignoux M, Stern C, Maylin S, Ripault MP, Boyer N, Leclere L, Castelnau C, Giuily N, El Ray A, Cardoso AC, et al. Twelve weeks posttreatment follow-up is as relevant as 24 weeks to determine the sustained virologic response in patients with hepatitis $c$ virus receiving pegylated interferon and ribavirin. Hepatology. 2010;51:1122-6.

4. Wen $Y$, Zheng $Y X$, de Tan M. A comprehensive long-term prognosis of chronic hepatitis $C$ patients with antiviral therapy: a meta-analysis of studies from 2008 to 2014. Hepat Mon. 2015;15:e27181.

5. Higgins JP, Green S. Cochrane handbook for systematic reviews of interventions. Version 5.1.0. The Cochrane Collaboration; 2011, 2013.

6. Stang A. Critical evaluation of the Newcastle-Ottawa scale for the assessment of the quality of nonrandomized studies in meta-analyses. Eur J Epidemiol. 2010;25:603-5.

7. Deeks JJ, Dinnes J, D'Amico R, Sowden AJ, Sakarovitch C, Song F, Petticrew M, Altman DG. Evaluating non-randomised intervention studies. Health Technol Assess. 2003;7:1-173. iii-x.

8. Higgins JP, Thompson SG. Quantifying heterogeneity in a meta-analysis. Stat Med. 2002;21:1539-58

9. Higgins JP, Thompson SG, Deeks JJ, Altman DG. Measuring inconsistency in meta-analyses. BMJ. 2003;327:557-60.

10. DerSimonian R, Laird N. Meta-analysis in clinical trials. Control Clin Trials. 1986;7:177-88. 
11. Duval S, Tweedie R. Trim and fill: a simple funnel-plot-based method of testing and adjusting for publication bias in meta-analysis. Biometrics. 2000;56:455-63.

12. Sutton AJ, Abrams KR, Jones DR, Sheldon TA, Song F. Methods for meta-analysis in medical research. Chichester (UK): Wiley; 2000.

13. Sterne JA, Egger M. Funnel plots for detecting bias in meta-analysis: guidelines on choice of axis. J Clin Epidemiol. 2001;54:1046-55.

14. Begg CB, Mazumdar M. Operating characteristics of a rank correlation test for publication bias. Biometrics. 1994;50:1088-101.

15. Egger M, Davey Smith G, Schneider M, Minder C. Bias in meta-analysis detected by a simple, graphical test. BMJ. 1997;315:629-34.

16. Testino G, Ansaldi F, Andorno E, Ravetti GL, Ferro C, De laco F, Icardi G, Valente $U$. Interferon therapy does not prevent hepatocellular carcinoma in HCV compensated cirrhosis. Hepatogastroenterology. 2002;49:1636-8.

17. Kasahara A, Tanaka H, Okanoue T, Imai Y, Tsubouchi H, Yoshioka K, Kawata S, Tanaka E, Hino K, Hayashi K, et al. Interferon treatment improves survival in chronic hepatitis $\mathrm{C}$ patients showing biochemical as well as virological responses by preventing liver-related death. J Viral Hepat. 2004;11:148-56.

18. Singal AK, Singh A, Jaganmohan S, Guturu P, Mummadi R, Kuo YF, Sood GK Antiviral therapy reduces risk of hepatocellular carcinoma in patients with hepatitis C virus-related cirrhosis. Clin Gastroenterol Hepatol. 2010;8:192-9.

19. Hung $\mathrm{CH}$, Lee $\mathrm{CM}$, Lu SN, Wang JH, Hu TH, Tung HD, Chen CH, Chen WJ, Changchien CS. Long-term effect of interferon alpha-2b plus ribavirin therapy on incidence of hepatocellular carcinoma in patients with hepatitis C virus-related cirrhosis. J Viral Hepat. 2006;13:409-14.

20. Gerotto M, Dal Pero F, Bortoletto G, Ferrari A, Pistis R, Sebastiani G, Fagiuoli S, Realdon S, Alberti A. Hepatitis C minimal residual viremia (MRV) detected by TMA at the end of Peg-IFN plus ribavirin therapy predicts post-treatment relapse. J Hepatol. 2006;44:83-7.

21. Miyake $Y$, Iwasaki Y, Yamamoto K. Meta-analysis: reduced incidence of hepatocellular carcinoma in patients not responding to interferon therapy of chronic hepatitis C. Int J Cancer. 2010;127:989-96.

22. Everson GT, Hoefs JC, Seeff LB, Bonkovsky HL, Naishadham D, Shiffman ML, Kahn JA, Lok AS, Di Bisceglie AM, Lee WM, et al. Impact of disease severity on outcome of antiviral therapy for chronic hepatitis C: lessons from the HALT-C trial. Hepatology. 2006;44:1675-84.

23. Mazzella G, Accogli E, Sottili S, Festi D, Orsini M, Salzetta A, Novelli V, Cipolla A, Fabbri C, Pezzoli A, et al. Alpha interferon treatment may prevent hepatocellular carcinoma in HCV-related liver cirrhosis. J Hepatol. 1996:24:141-7.

24. Bruno S, Silini E, Crosignani A, Borzio F, Leandro G, Bono F, Asti M, Rossi S, Larghi A, Cerino A, et al. Hepatitis C virus genotypes and risk of hepatocellular carcinoma in cirrhosis: a prospective study. Hepatology. 1997; 25:754-8.

25. Fattovich G, Giustina G, Degos F, Diodati G, Tremolada F, Nevens F, Almasio P, Solinas A, Brouwer JT, Thomas $H$, et al. Effectiveness of interferon Alfa on incidence of hepatocellular carcinoma and decompensation in cirrhosis type C. European concerted action on viral hepatitis (EUROHEP). J Hepatol. 1997:27:201-5.

26. Serfaty L, Aumaitre $H$, Chazouilleres O, Bonnand AM, Rosmorduc O, Poupon RE, Poupon R. Determinants of outcome of compensated hepatitis C virus-related cirrhosis. Hepatology. 1998;27:1435-40.

27. Benvegnu L, Chemello L, Noventa F, Fattovich G, Pontisso P, Alberti A. Retrospective analysis of the effect of interferon therapy on the clinical outcome of patients with viral cirrhosis. Cancer. 1998;83:901-9.

28. International Interferon-alpha Hepatocellular Carcinoma Study Group. Effect of interferon-alpha on progression of cirrhosis to hepatocellular carcinoma: a retrospective cohort study. Lancet. 1998;351:1535-9.

29. Imai Y, Kawata S, Tamura S, Yabuuchi I, Noda S, Inada M, Maeda Y, Shirai Y, Fukuzaki T, Kaji I, et al. Relation of interferon therapy and hepatocellular carcinoma in patients with chronic hepatitis C. Osaka hepatocellular carcinoma prevention study group. Ann Internal Med. 1998;129:94-9.

30. Yoshida $H$, Shiratori $Y$, Moriyama M, Arakawa $Y$, Ide T, Sata M, Inoue $O$, Yano M, Tanaka M, Fujiyama $S$, et al. Interferon therapy reduces the risk for hepatocellular carcinoma: national surveillance program of cirrhotic and noncirrhotic patients with chronic hepatitis C in Japan. IHIT study group. Inhibition of hepatocarcinogenesis by interferon therapy. Ann Internal Med. 1999;131:174-81.

31. Okanoue T, Itoh Y, Minami M, Sakamoto S, Yasui K, Sakamoto M, Nishioji K, Murakami Y, Kashima K. Interferon therapy lowers the rate of progression to hepatocellular carcinoma in chronic hepatitis $\mathrm{C}$ but not significantly in an advanced stage: a retrospective study in 1148 patients. Viral hepatitis therapy study group. J Hepatol. 1999;30:653-9.

32. Valla DC, Chevallier M, Marcellin P, Payen JL, Trepo C, Fonck M, Bourliere M, Boucher E, Miguet JP, Parlier D, et al. Treatment of hepatitis $C$ virus-related cirrhosis: a randomized, controlled trial of interferon alfa- $2 \mathrm{~b}$ versus no treatment. Hepatology. 1999;29:1870-5.

33. Ikeda K, Saitoh S, Kobayashi M, Suzuki Y, Suzuki F, Tsubota A, Arase Y, Murashima N, Chayama K, Kumada H. Long-term interferon therapy for 1 year or longer reduces the hepatocellular carcinogenesis rate in patients with liver cirrhosis caused by hepatitis C virus: a pilot study. J Gastroenterol Hepatol. 2001;16:406-15.

34. Gramenzi A, Andreone P, Fiorino S, Cammà C, Giunta M, Magalotti D, Cursaro C, Calabrese C, Arienti V, Rossi C, et al. Impact of interferon therapy on the natural history of hepatitis C virus related cirrhosis. Gut. 2001;48:843-8.

35. Nishiguchi S, Shiomi S, Nakatani S, Takeda T, Fukuda K, Tamori A, Habu D, Tanaka T. Prevention of hepatocellular carcinoma in patients with chronic active hepatitis C and cirrhosis. Lancet. 2001;357:196-7.

36. Coverdale SA, Khan MH, Byth K, Lin R, Weltman M, George J,

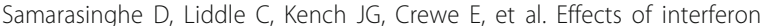
treatment response on liver complications of chronic hepatitis C: 9-years follow-up study. Am J Gastroenterol. 2004;99:636-44

37. Azzaroli F, Accogli E, Nigro G, Trere D, Giovanelli S, Miracolo A, Lodato F, Montagnani M, Tamé M, Colecchia A, et al. Interferon plus ribavirin and interferon alone in preventing hepatocellular carcinoma: a prospective study on patients with HCV related cirrhosis. World J Gastroenterol. 2004;10: 3099-102.

38. Shiratori $Y$, Ito $Y$, Yokosuka O, Imazeki F, Nakata R, Tanaka N, Arakawa Y, Hashimoto E, Hirota K, Yoshida H, et al. Antiviral therapy for cirrhotic hepatitis C: association with reduced hepatocellular carcinoma development and improved survival. Ann Internal Med. 2005:142:105-14.

39. Yu ML, Lin SM, Chuang WL, Dai CY, Wang JH, Lu SN, Sheen IS, Chang WY, Lee CM, Liaw YF. A sustained virological response to interferon or interferon/ribavirin reduces hepatocellular carcinoma and improves survival in chronic hepatitis C: a nationwide, multicentre study in Taiwan. Antivir Ther. 2006;11:985-94.

40. Sinn DH, Paik SW, Kang P, Kil JS, Park SU, Lee SY, Song SM, Gwak GY, Choi MS, Lee $\mathrm{JH}$, et al. Disease progression and the risk factor analysis for chronic hepatitis C. Liver Int. 2008;28:1363-9.

41. Di Martino V, Crouzet J, Hillon P, Thévenot T, Minello A, Monnet E. Long-term outcome of chronic hepatitis $C$ in a population-based cohort and impact of antiviral therapy: a propensity-adjusted analysis. J Viral Hepat. 2011;18:493-505.

42. Tateyama M, Yatsuhashi H, Taura N, Motoyoshi Y, Nagaoka S, Yanagi K, Abiru S, Yano K, Komori A, Migita K, et al. Alpha-fetoprotein above normal levels as a risk factor for the development of hepatocellular carcinoma in patients infected with hepatitis C virus. J Gastroenterol. 2011;46:92-100.

43. Maruoka D, Imazeki F, Arai M, Kanda T, Fujiwara K, Yokosuka O. Long-term cohort study of chronic hepatitis $C$ according to interferon efficacy. J Gastroenterol Hepatol. 2012:27:291-9.

44. Cozen ML, Ryan JC, Shen H, Lerrigo R, Yee RM, Sheen E, Wu R, Monto A. Nonresponse to interferon-alpha based treatment for chronic hepatitis $C$ infection is associated with increased hazard of cirrhosis. PLoS One. 2013;8: e61568.

45. Aleman S, Rahbin N, Weiland O, Davidsdottir L, Hedenstierna M, Rose N, Verbaan H, Stål P, Carlsson T, Norrgren H, et al. A risk for hepatocellular carcinoma persists long-term after sustained virologic response in patients with hepatitis C-associated liver cirrhosis. Clin Infect Dis. 2013;57:230-6.

46. Cozen ML, Ryan JC, Shen H, Cheung R, Kaplan DE, Pocha C, Brau N, Aytaman A, Schmidt WN, Pedrosa M, et al. Improved survival among all interferon-alpha-treated patients in HCV-002, a veterans affairs hepatitis C cohort of 2211 patients, despite increased cirrhosis among nonresponders. Dig Dis Sci. 2016;61:1744-56.

47. Yoshida H, Arakawa Y, Sata M, Nishiguchi S, Yano M, Fujiyama S, Yamada G, Yokosuka O, Shiratori Y, Omata M. Interferon therapy prolonged life expectancy among chronic hepatitis C patients. Gastroenterology. 2002;123:483-91.

48. Imazeki F, Yokosuka O, Fukai K, Saisho H. Favorable prognosis of chronic hepatitis $C$ after interferon therapy by long-term cohort study. Hepatology. 2003:38:493-502.

49. Yamasaki K, Tomohiro M, Nagao Y, Sata M, Shimoda T, Hirase K, Shirahama S. Effects and outcomes of interferon treatment in Japanese hepatitis C patients. BMC Gastroenterol. 2012;12:139. 
50. Kutala BK, Guedj J, Asselah T, Boyer N, Mouri F, Martinot-Peignoux M, Valla D, Marcellin P, Duval X. Impact of treatment against hepatitis C virus on overall survival of naive patients with advanced liver disease. Antimicrob Agents Chemother. 2015;59:803-10.

51. Nishiguchi S, Kuroki T, Nakatani S, Morimoto H, Takeda T, Nakajima S, Shiomi S, Seki S, Kobayashi K, Otani S. Randomised trial of effects of interferon-alpha on incidence of hepatocellular carcinoma in chronic active hepatitis C with cirrhosis. Lancet. 1995;346:1051-5.

52. Tanaka K, Sata M, Uchimura Y, Suzuki H, Tanikawa K. Long-term evaluation of interferon therapy in hepatitis C virus-associated cirrhosis: does IFN prevent development of hepatocellular carcinoma? Oncol Rep. 1998;5:205-8.

53. Okanoue T, Itoh Y, Kirishima T, Daimon Y, Toyama T, Morita A, Nakajima T, Minami M. Transient biochemical response in interferon therapy decreases the development of hepatocellular carcinoma for 5 years and improves the I ong-term survival of chronic hepatitis C patients. Hepatol Res. 2002;23:62-77.

54. Pradat P, Tillmann HL, Sauleda S, Braconier JH, Saracco G, Thursz M, Goldin R, Winkler R, Alberti A, Esteban Jl, et al. Long-term follow-up of the hepatitis C HENCORE cohort: response to therapy and occurrence of liver-related complications. J Viral Hepat. 2007:14:556-63.

55. Braks RE, Ganne-Carrie N, Fontaine H, Paries J, Grando-Lemaire V, Beaugrand M, Pol S, Trinchet JC. Effect of sustained virological response on long-term clinical outcome in 113 patients with compensated hepatitis C-related cirrhosis treated by interferon alpha and ribavirin. World J Gastroenterol. 2007:13:5648-53.

56. Bruno S, Stroffolini T, Colombo M, Bollani S, Benvegnù L, Mazzella G, Ascione A, Santantonio T, Piccinino F, Andreone P, et al. Sustained virological response to interferon-alpha is associated with improved outcome in HCV-related cirrhosis: a retrospective study. Hepatology. 2007:45:579-87.

57. Hasegawa E, Kobayashi M, Kawamura Y, Yatsuji H, Sezaki H, Hosaka T, Akuta N, Suzuki F, Suzuki Y, Arase Y, et al. Efficacy and anticarcinogenic activity of interferon for hepatitis C virus-related compensated cirrhosis in patients with genotype 1b low viral load or genotype 2. Hepatol Res. 2007;37:793-800.

58. Veldt BJ, Heathcote EJ, Wedemeyer $\mathrm{H}$, Reichen J, Hofmann WP, Zeuzem S, Manns MP, Hansen BE, Schalm SW, Janssen HL. Sustained virologic response and clinical outcomes in patients with chronic hepatitis $C$ and advanced fibrosis. Ann Intern Med. 2007;147:677-84.

59. Floreani A, Baldo V, Rizzotto ER, Carderi I, Baldovin T, Minola E. Pegylated interferon alpha-2b plus ribavirin for naive patients with HCV-related cirrhosis. J Clin Gastroenterol. 2008:42:734-7.

60. Kurokawa M, Hiramatsu N, Oze T, Mochizuki K, Yakushijin T, Kurashige N, Inoue $Y$, Igura T, Imanaka K, Yamada A, et al. Effect of interferon alpha-2b plus ribavirin therapy on incidence of hepatocellular carcinoma in patients with chronic hepatitis. Hepatol Res. 2009;39:432-8.

61. Asahina Y, Tsuchiya K, Tamaki N, Hirayama I, Tanaka T, Sato M, Yasui Y, Hosokawa T, Ueda K, Kuzuya T, et al. Effect of aging on risk for hepatocellular carcinoma in chronic hepatitis C virus infection. Hepatology. 2010;52:518-27.

62. Kawamura $Y$, Arase $Y$, Ikeda $K$, Hirakawa M, Hosaka T, Kobayashi M, Saitoh S, Yatsuji $H$, Sezaki H, Akuta N, et al. Diabetes enhances hepatocarcinogenesis in noncirrhotic, interferon-treated hepatitis C patients. Am J Med. 2010;123: 951-6.e1.

63. Cardoso AC, Moucari R, Figueiredo-Mendes C, Ripault MP, Giuily N, Castelnau C, Boyer N, Asselah T, Martinot-Peignoux M, Maylin S, et al. Impact of peginterferon and ribavirin therapy on hepatocellular carcinoma: incidence and survival in hepatitis C patients with advanced fibrosis. J Hepatol. 2010;52:652-7.

64. Morgan TR, Ghany MG, Kim HY, Snow KK, Shiffman ML, De Santo JL, Lee WM, Di Bisceglie AM, Bonkovsky HL, Dienstag JL, et al. Outcome of sustained virological responders with histologically advanced chronic hepatitis $C$ Hepatology. 2010;52:833-44.

65. Velosa J, Serejo F, Marinho R, Nunes J, Glória H. Eradication of hepatitis C virus reduces the risk of hepatocellular carcinoma in patients with compensated cirrhosis. Dig Dis Sci. 2011:56:1853-61.

66. lacobellis A, Perri F, Valvano MR, Caruso N, Niro GA, Andriulli A. Long-term outcome after antiviral therapy of patients with hepatitis $C$ virus infection and decompensated cirrhosis. Clin Gastroenterol Hepatol. 2011;9:249-53.

67. Hung $\mathrm{CH}$, Lee $\mathrm{CM}$, Wang $\mathrm{JH}$, Hu TH, Chen CH, Lin CY, Lu SN. Impact of diabetes mellitus on incidence of hepatocellular carcinoma in chronic hepatitis C patients treated with interferon-based antiviral therapy. Int J Cancer. 2011;128:2344-52.
68. Takahashi H, Mizuta T, Eguchi Y, Kawaguchi Y, Kuwashiro T, Oeda S, Isoda H, Oza N, Iwane S, Izumi K, et al. Post-challenge hyperglycemia is a significant risk factor for the development of hepatocellular carcinoma in patients with chronic hepatitis C. J Gastroenterol. 2011;46:790-8.

69. Backus LI, Boothroyd DB, Phillips BR, Belperio P, Halloran J, Mole LA. A sustained virologic response reduces risk of all-cause mortality in patients with hepatitis C. Clin Gastroenterol Hepatol. 2011;9:509-16.e1.

70. Osaki Y, Ueda Y, Marusawa H, Nakajima J, Kimura T, Kita R, Nishikawa H, Saito S, Henmi S, Sakamoto A, et al. Decrease in alpha-fetoprotein levels predicts reduced incidence of hepatocellular carcinoma in patients with hepatitis $C$ virus infection receiving interferon therapy: a single center study. J Gastroenterol. 2012;47:444-51.

71. van der Meer AJ, Veldt BJ, Feld JJ, Wedemeyer H, Dufour JF, Lammert F, Duarte-Rojo A, Heathcote EJ, Manns MP, Kuske L, et al. Association between sustained virological response and all-cause mortality among patients with chronic hepatitis C and advanced hepatic fibrosis. JAMA. 2012;308:2584-93.

72. Alfaleh FZ, Alswat K, Helmy A, Al-hamoudi W, El-sharkawy M, Omar M, Shalaby A, Bedewi MA, Hadad Q, Ali SM, et al. The natural history and long-term outcomes in patients with chronic hepatitis $C$ genotype 4 after interferon-based therapy. Liver Int. 2013;33:871-83.

73. Di Marco V, Calvaruso V, Ferraro D, Ferraro D, Bavetta MG, Cabibbo G, Conte E, Cammà C, Grimaudo S, Pipitone RM, et al. Effects of Viral Eradication in Patients with HCV and Cirrhosis Differ With Stage of Portal Hypertension. Gastroenterology. 2016;151:130-139.e2.

74. Ikezaki H, Nomura H, Furusyo N, Ogawa E, Kajiwara E, Takahashi K, Kawano A, Maruyama T, Tanabe Y, Satoh T, et al. Efficacy of interferon-beta plus ribavirin combination treatment on the development of hepatocellular carcinoma in Japanese patients with chronic hepatitis C. Hepatol Res. 2016;46:E174-80.

75. Arase Y, Ikeda K, Suzuki F, Suzuki Y, Saitoh S, Kobayashi M, Akuta N, Someya T, Koyama R, Hosaka T, et al. Long-term outcome after interferon therapy in elderly patients with chronic hepatitis C. Intervirology. 2007;50:16-23.

76. Innes HA, Hutchinson SJ, Allen S, Bhattacharyya D, Bramley P, Delahooke TE, Dillon JF, Forrest E, Fraser A, Gillespie R, et al. Excess liver-related morbidity of chronic hepatitis C patients, who achieve a sustained viral response, and are discharged from care. Hepatology. 2011:54:1547-58.

77. Singal AG, Dharia TD, Malet PF, Alqahtani S, Zhang S, Cuthbert JA. Long-term benefit of hepatitis $C$ therapy in a safety net hospital system: a cross-sectional study with median 5-year follow-up. BMJ Open. 2013;3:e003231.

78. Dieperink E, Pocha C, Thuras P, Knott A, Colton S, Ho SB. All-cause mortality and liver-related outcomes following successful antiviral treatment for chronic hepatitis C. Dig Dis Sci. 2014;59:872-80.

\section{Submit your next manuscript to BioMed Central and we will help you at every step:}

- We accept pre-submission inquiries

- Our selector tool helps you to find the most relevant journal

- We provide round the clock customer support

- Convenient online submission

- Thorough peer review

- Inclusion in PubMed and all major indexing services

- Maximum visibility for your research

Submit your manuscript at www.biomedcentral.com/submit
) Biomed Central 